\title{
Impact of atmospheric circulations on aerosol distributions in autumn over eastern China: observational evidence
}

\author{
X. Y. Zheng ${ }^{1}$, Y. F. Fu ${ }^{1,2,3}$, Y. J. Yang ${ }^{1,3}$, and G. S. Liu ${ }^{1,4}$ \\ ${ }^{1}$ School of Earth and Space Sciences, University of Science and Technology of China, Hefei, 230026, PR China \\ ${ }^{2}$ State Key Laboratory of Severe Weather, Chinese Academy of Meteorological Sciences, Beijing, 100081, PR China \\ ${ }^{3}$ Key Laboratory of Atmospheric Sciences and Satellite Remote Sensing of Anhui Province, Anhui Institute of \\ Meteorological Sciences, Hefei, 230031, PR China \\ ${ }^{4}$ Department of Meteorology, Florida State University, Tallahassee, FL 32306-4520, USA
}

Correspondence to: Y. F. Fu (fyf@ustc.edu.cn)

Received: 18 November 2014 - Published in Atmos. Chem. Phys. Discuss.: 5 February 2015

Revised: 24 September 2015 - Accepted: 7 October 2015 - Published: 2 November 2015

\begin{abstract}
Regional heavy pollution events in eastern China $\left(110-122^{\circ} \mathrm{E}, 28-40^{\circ} \mathrm{N}\right)$ are causing serious environmental problems. In this study, the relationship between the degree of regional pollution and the patterns of large-scale atmospheric circulation over eastern China in October is investigated using 10-year (2001-2010) Terra/MODIS aerosol optical depth and NCEP reanalysis data by both case study and composite analysis. Eighteen polluted and 10 clean episodes are selected and categorised into six polluted types and three clean types respectively. Generally speaking, weather patterns such as a uniform surface pressure field in eastern China or a steady straight westerly in the middle troposphere, particularly when being at the rear of the anticyclone at $850 \mathrm{hPa}$, are typically responsible for heavy pollution events. Meanwhile, clean episodes occur when strong southeastward cold air advection prevails below the middle troposphere or air masses are transported from sea to land. Uniform descending motion prevails over the study region, trapping pollutants in the lower atmosphere. Therefore, the value of vertical velocity averaged from 1000 to $100 \mathrm{hPa}$ and divergence of wind field in the lower troposphere are used in this study to quantify the diffusion conditions in each circulation type. The results reveal that it is often a clean episode when both the mean downward motion (larger than $2.56 \times 10^{-2} \mathrm{~Pa} \mathrm{~s}^{-1}$ ) and the divergence of lowlevel winds (larger than $1.79 \times 10^{-2} \mathrm{~s}^{-1}$ ) are strong. Otherwise, it is more likely to be a polluted episode.
\end{abstract}

\section{Introduction}

Since aerosols can modulate the radiation budget of the earth-atmosphere system, influence the climate and degrade air quality (Kaufman et al., 2002), they have long been attracting high attentions from scientific community (Twomey, 1977; Rosenfeld et al., 2004; Zhao et al., 2006a, b; Rosenfeld et al., 2007; Li et al., 2011; Koren et al., 2012; Zhao et al., 2012, 2013a, b; Chen et al., 2014). Particularly with rapid urban growth and the development of various industries during the last decades, the high concentration of atmospheric pollutants has become a major environmental problem, which poses a threat to human health (Donaldson et al., 2001; Kan and Chen, 2004; Janssen et al., 2011). To understand the mechanisms that control spatiotemporal distribution of aerosols, extensive investigations have been carried out to study the relationship between air quality and multiple factors. Among the multifaceted problems related to air pollution, favourable weather conditions are a factor that should not be ignored (Zhao et al., 2010; Xu et al., 2011). In general, although the characteristics of regional air quality depend on many complex elements, the major contributors are the emission of the pollutants and favourable largescale meteorological conditions (Z. H. Chen et al., 2008; X. L. Chen et al., 2008). Ziomas et al. (1995) pointed out that in an urban environment, the serious air pollution episodes are not attributed to sudden increases in the emission of pollutants but caused by meteorological conditions that are unfavourable for dispersion. Normally, the anthropogenic emissions of widespread pollutant sources are quasi-stable in east- 
ern China, and the degree of air pollution in the region is largely subject to large-scale atmospheric conditions (Xu et al., 2011). In some other regions, strong links between the concentration of aerosols and certain synoptic weather condition have already been identified (Demuzere et al., 2009; Saavedra et al., 2012). It has also been revealed that under the circumstances of the same pollutant emission quantity, the ground concentration of pollutants varies directly with different synoptic patterns (Wang et al., 2013).

Weather conditions as represented by a number of meteorological parameters, such as wind speed and direction, temperature, relative humidity and precipitation, and synoptic patterns as analysed in terms of atmospheric circulations can contribute to the vertical redistribution and long-range transport of air pollutants, which leads to either accumulation or dispersion of aerosols (Cheng et al., 2007; Ding et al., 2009). A growing body of research is showing the important effects of weather conditions on determining the distribution of pollutants and atmospheric pollution levels. For example, Tanner and Law (2002) investigated the impact of meteorological parameters (wind speed, wind direction, temperature, relative humidity and solar radiation intensity) on the frequency of high-level polluted episodes in Hong Kong. Ding et al. (2004) successfully simulated the wind patterns of sea-land breezes and the planetary boundary layer heights to illustrate the meteorological cause of the photochemical ozone episode associated with Typhoon Nari in the Pearl River Delta of China. They compared the characteristics of dispersion and transport during pre-episode and episode days. Xu et al. (2011) confirmed the deterministic impact of wind speed and wind direction on the concentration of various trace gases at a suburban site between two mega-cities. Csavina et al. (2014) examined dust events in two semi-arid sites and then showed a complex, nonlinear dependence of $\mathrm{PM}_{10}$ (particulate matter with aerodynamic diameters $\leq 10 \mu \mathrm{m}$ ) on wind speed and relative humidity.

The synoptic-scale circulations represent a certain atmospheric condition at a given region through its close association with various meteorological parameters such as wind speed, wind direction and temperature (Shahgedanova et al., 1998; Kassomenos et al., 2003; Chen et al., 2009). Consequently, instead of using individual meteorological parameters, several studies have been carried out based on atmospheric circulation patterns. For example, Shahgedanova (1998) employed principal component analysis and cluster analysis for Moscow to develop seasonal synoptic indices to examine weather-induced variability in carbon monoxide $(\mathrm{CO})$ and nitrogen dioxide $\left(\mathrm{NO}_{2}\right)$ concentrations and concluded that anticyclonic conditions in spring, summer and autumn are introductive to high pollution levels. Flocas et al. (2008) assessed the circulation patterns at the mean sea level for a period of 15 years and distinguished four synoptic-scale types. They found the presence of an anticyclone accounted for the highest percentage of polluted episode over Greece. Moreover, Zhang et al. (2010) used a numerical model to simulate the impact of weak/strong monsoon circulations on interannual variations of aerosols over eastern China under the conditions of the same anthropogenic emissions and suggested that the decadal-scale weakening of the East Asian summer monsoon is responsible for the increase in aerosol concentrations over eastern China. Using satellite products, Zhao et al. (2010) showed consistent disappearance of $\mathrm{CO}$ and ozone $\left(\mathrm{O}_{3}\right)$ enhancements over southeastern China at the onset of East Asian summer monsoon and the reemergence after the monsoon wanes, which confirmed the strong modulation of monsoon system on regional air quality. Liu et al. (2013) further demonstrated a potential influence from the variation of large-scale circulation, El Niño-Southern Oscillation, upon the interannual fluctuation of summertime aerosol optical depth (AOD). Russo et al. (2014) applied the analysis on 10 basic circulation weather types characterized by a set of indices, and their results showed that easterlies prevailed during polluted episodes of three pollutants $\left(\mathrm{NO}_{2}, \mathrm{PM}_{10}, \mathrm{O}_{3}\right)$ in Portugal.

The aforementioned works suggest that synoptic types play a crucial role in the formation of a polluted episode. They established a predictive connection between air quality and circulation pattern over various regions and provided valuable scientific basis for weather forecast operations. To the authors' knowledge, even though some attempts have been conducted to study similar relationships in China, most study the connection over a single city (Wang et al., 2007; X. L. Chen et al., 2008; Guo et al., 2013) rather than over a regional scale (e.g. eastern China in this study). Eastern China, as a highly urbanised region, with the rapid increase of industrial and automotive emissions, is frequently characterized by poor air quality (Ding et al., 2008; He et al., 2012). Therefore, establishing a predictable relationship between circulation pattern and air quality is important for early prediction of polluted episodes.

In the present study, we evaluate the above relationship during autumn using 10-year (2001-2010) Terra/MODIS (Moderate-resolution Imaging Spectroradiometer) AOD product and atmospheric circulations derived from National Centers for Environmental Prediction (NCEP) reanalysis data. The choice of autumn is in consideration of the following reasons. First, the wet deposition effect is weaker due to less precipitation in autumn (Chen et al., 2012), which also ensures the availability of AOD data. Second, in contrast with other seasons, the local atmosphere structure of autumn is stable and mainly influenced by large-scale synoptic systems; the dynamic impact is stronger than the thermal effect. These features reduce the influences of complex mesoscale and small-scale weather systems and the thermal effect on precipitation. Therefore, precipitation in this season tends to be caused by certain large-scale atmospheric circulations, which makes it more suitable for the study of the impact of large-scale atmospheric circulations. Finally, previous research rarely focused on the polluted episodes during autumn. In addition, Anhui province is taken as an ex- 
ample to show the pollution level of each month in eastern China (Yang et al., 2013). The occurring frequency of haze days for Anhui is the highest in October during a whole year based on the measurements from 80 meteorological observation stations. Therefore, October is selected as a representative autumn month for our present work. The rest of the paper is organised as follows. A brief description of the data and processing methodology used in this study is presented in Sect. 2. In Sects. 3 and 4, we describe the interannual variability of AOD over eastern China and then explore the relationships between AOD and characteristics of synoptic circulations through statistical and synthetic analysis. Conclusions are given in Sect. 5, in which the association of various circulation types with different AOD spatial distributions over eastern China is summarised.

\section{Data and methods}

Data used in this study and methods for selecting high/low AOD cases are described in this section. The research considers the time period from 2001 to 2010 over the region of 28 to $40^{\circ} \mathrm{N}$ and 110 to $122^{\circ} \mathrm{E}$.

\subsection{Pollution data}

The main data set used to describe air quality is the daily averaged Collection 5.1 level 3 AOD products (at $1^{\circ}$ horizontal resolution) derived from the Terra's MODIS measurements (accessible from http://ladsweb.nascom.nasa.gov/ data/search.html). Unlike ground-based data, MODIS provides long-term continuous observations for the spatial and temporal distribution of aerosol, suitable for the investigation of this study. AOD measures the degree to which aerosols prevent the transmission of light by scattering and absorption. By using the Terra/MODIS aerosol data, Kim et al. (2007) evaluated the temporal and spatial variation of aerosols over East Asia. Wu et al. (2013) pointed out that MODIS data were usually valid throughout China and revealed the characteristics of aerosol transport and different extinction features in East Asia. Luo et al. (2014) verified the good quality of MODIS AOD over land in China and used 10-year data to construct the climatology of AOD over China. Based on the previous validations, MODIS AOD data are considered to have good quality over China region and can capture the features of aerosol distribution.

In fact, the AOD data have been widely used to enhance the understanding of changes in air quality over local, regional and global scales as a result of their sensitivity to total abundance of aerosols (Chu et al., 2002; Al-Saadi et al., 2005; Lin et al., 2010). AOD can indicate the air quality to a certain degree; the higher the AOD value is, the worse air quality becomes (Liu et al., 2013). In this study, we discuss the cases of polluted and clean air separately.
Finally, the Collection 5 MODIS active fire product (MCD14ML) is used to monitor the influences of the sudden enhanced emissions from biomass burning. The monthly fire location product contains the geographic location, date and some additional information for each fire pixel on a monthly basis. In this study, only those Terra-observed pixels with fire detection confidence greater than $60 \%$ are used.

\subsection{Meteorological data}

The corresponding atmospheric field analyses performed in this paper are based on the results of meteorological reanalysis products made available by NCEP and National Center for Atmospheric Research (NCAR). For a complete discussion, we consider both the surface and upper-air circulation patterns. The sea level pressure field, which is closely related to the meteorological factors, is selected to characterise a certain synoptic episode. The 850 and $500 \mathrm{hPa}$ levels are selected as the typical height of the lower and middle troposphere respectively. Mean sea level pressure, temperatures at the surface and $500 \mathrm{hPa}$, geopotential heights at the 850 and $500 \mathrm{hPa}$ levels as well as relative humidity, wind field and vertical velocity were extracted from NCEP/NCAR Reanalysis data set on a $2.5^{\circ} \times 2.5^{\circ}$ latitude/longitude grid on a daily basis (http://www.esrl.noaa.gov/psd/data/gridded/data. ncep.reanalysis.html).

\subsection{Methods}

On the basis of 10-year October data, namely 310 days, we get the daily AOD distribution. According to the threshold of AOD (mentioned in Sect. 3.1), the whole 310 days are divided into four categories: high AOD (>0.6), low AOD $(<0.4)$, moderate AOD (0.4-0.6) and the missing-value day (due to clouds). Ignoring the group of missing and moderate AOD data, the circulation fields corresponding to the other two categories (high AOD and low AOD) are evaluated at the same time. Since satellite-based AOD exists certain uncertainties, the consecutive days of high (or low) value can better illustrate the existence of the air pollution than just 1 day. And statistical results of two categories also show that the occurrence of high (or low) value of AOD tends to last for several days. Additionally, the corresponding circulation pattern is also quasi-steady during these high (or low) AOD periods.

Taking the above facts into account, the first synthetic process is conducted by averaging the corresponding grid point values for a number of successive days (greater than or equal to 2 days) to represent high (or low) AOD conditions. Following this approach, 28 episodes, among which there are 18 high-value episodes (HEs) and 10 low-value episodes (LEs), are initially identified during 2001-2010. In order to obtain the statistical characteristics of the pollution and clean episodes, the second synthetic process is performed. We classify the $18 \mathrm{HEs}$ and 10LEs obtained in the first step on a 

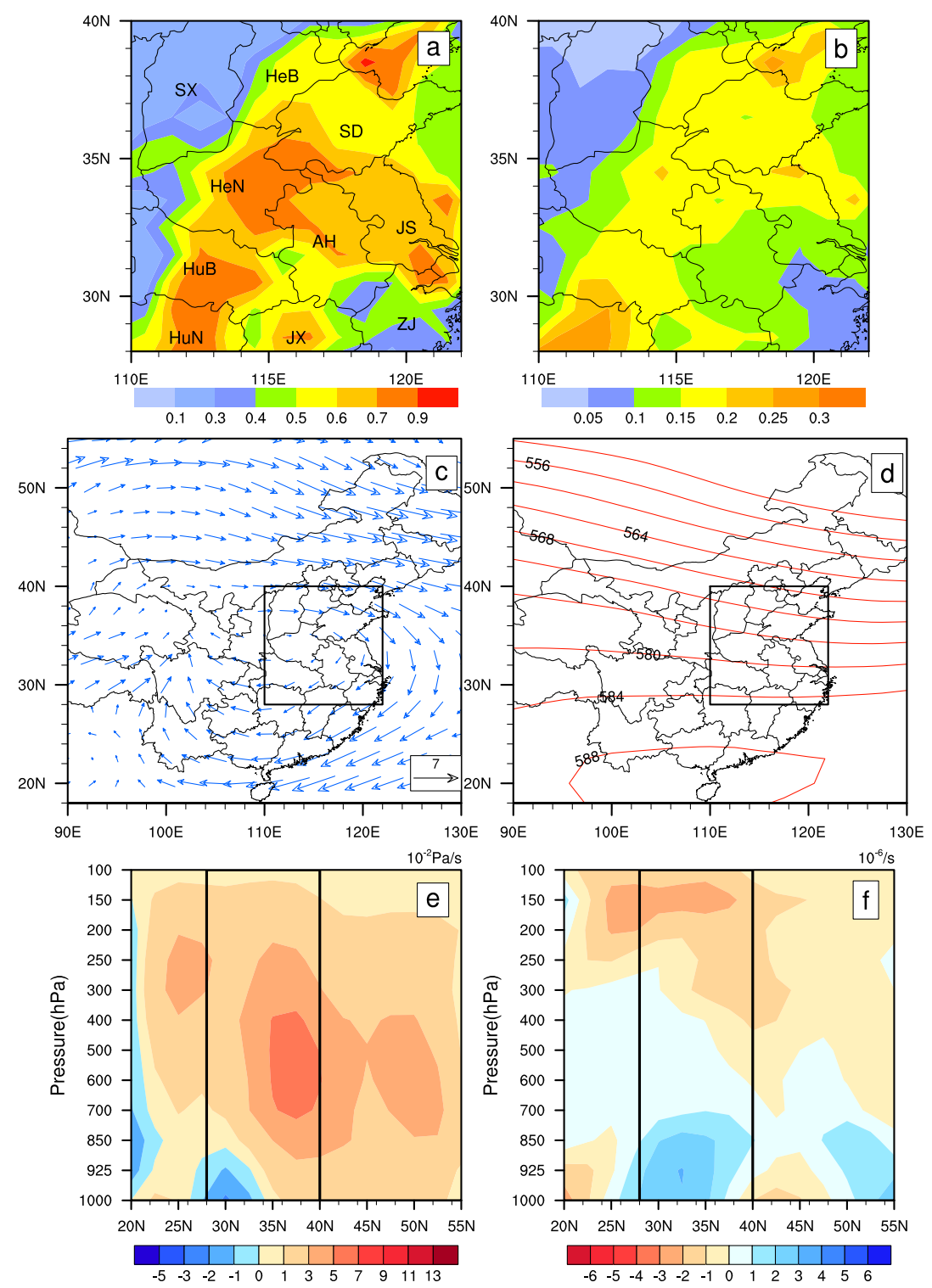

Figure 1. The mean distribution of (a) aerosol optical depth (AOD), (b) the standard deviation of AOD, (c) $850 \mathrm{hPa}$ winds field, (d) $500 \mathrm{hPa}$ geopotential height field, (e) height-latitude cross-sections of vertical velocity $\left(10^{-2} \mathrm{~Pa} \mathrm{~s}^{-1}\right)$ and (f) divergence of winds $\left(10^{-6} \mathrm{~s}^{-1}\right)$ averaged from longitude of $110-122^{\circ} \mathrm{E}$ in October for the period from 2001 to 2010. Black letters on Fig. 1a indicate the different provinces. SX: Shanxi; SD: Shandong; HeB: Hebei; HeN: Henan; HuB: Hubei; HuN: Hunan; AH: Anhui; JX: Jiangxi; JS: Jiangsu; ZJ: Zhejiang. Note: (c)-(f) indicate the circulations over East Asia $\left(18-55^{\circ} \mathrm{N}, 90-130^{\circ} \mathrm{E}\right)$ and black rectangular regions in this and subsequent figures represent eastern China $\left(28-40^{\circ} \mathrm{N}, 110-122^{\circ} \mathrm{E}\right)$, the region on which this study is focused.

synoptic basis and average the similar circulations for these two different categories respectively, a thorough description of results obtained by this method can be found in Sect. 3.3. The 18 HEs are clustered into six types while the 10 LEs are three types. Thus, nine distinct circulation types are consequently considered in the following analyses.

\subsection{Hybrid Single-Particle Lagrangian Integrated Trajectory (HYSPLIT) Model}

The backward trajectories for two typical episodes discussed in Sect 3.2 are simulated using the HYSPLIT model, employing NCEP/NCAR reanalysis meteorological data as input fields. With powerful computational capabilities, the HYSPLIT_4 model is a widely used system for calculating simple trajectories to complex dispersion and deposition simulations using either puff or particle approach (readers are re- 

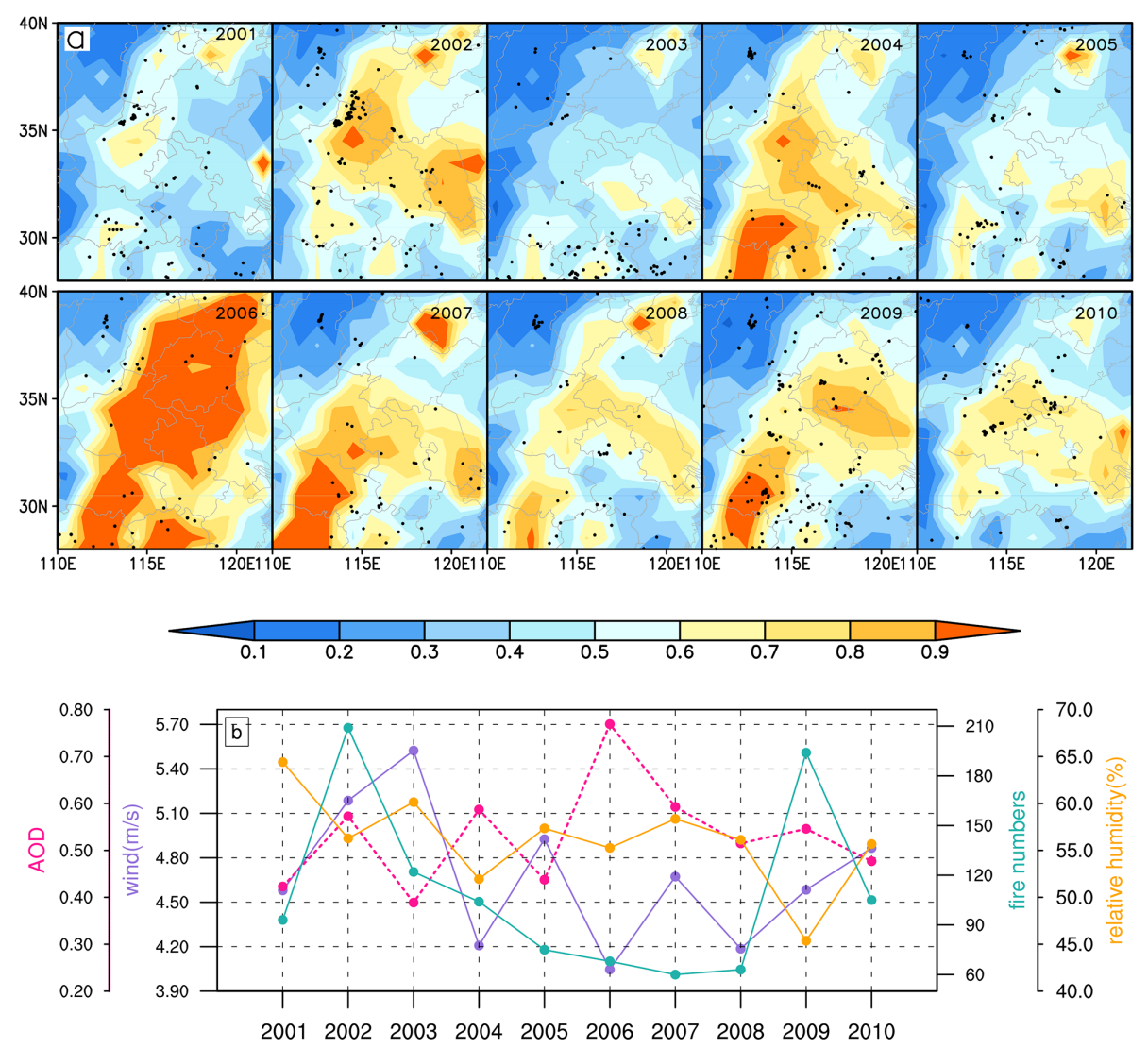

Figure 2. (a) The distribution of AOD over eastern China in October for 2001-2010. The black dots are fire locations. (b) Interannual variability of column AOD (peach). The number of fires is in green. Wind speed (purple) and relative humidity (orange) are averages in the lower troposphere (1000-850 hPa) and over the region shown in (a).

ferred to Draxler and Hess (1997) for details of the model). Borge et al. (2007) used back trajectories computed with HYSPLIT model to examine the impact of long-range atmospheric transport on urban $\mathrm{PM}_{10}$ for three cities. Chen et al. (2013) incorporated eight size fractions $(<0.33,0.66,1.3$, $2.5,5,14,17$ and $>17 \mu \mathrm{m}$ ) of PM of metals to the HYSPLIT model and provided a prediction of the size distribution and concentrations of heavy metals. In this work, the air-mass trajectories are evaluated in order to present the different movements of air parcels during the two opposite episodes.

\section{Results}

\subsection{Climatological mean and interannual variation}

Prior to the analysis of the link between air quality and largescale circulations, it is necessary to reveal the climatological mean and interannual variation of AOD in October over eastern China. The climatological mean AOD is obtained for the period from 2001 to 2010. As shown in Fig. 1a, the spatial distribution shows that AOD ranges from 0.3 to 0.9 for almost the entire area. Four prominent centres of high AOD values are found in eastern China, i.e. Bohai Gulf, Yangtze River delta, junctional areas of Anhui, Shandong and Henan provinces and most parts of Hubei and Hunan provinces. These regions were recognised as the source of high emissions in October according to Wang and Zhang (2008) and Yang et al. (2013). In other words, these centres are considered as possible consequences of industrial emissions or agricultural biomass burning that occurs in autumn under certain meteorological conditions. Figure $1 \mathrm{~b}$ presents the standard deviation of AOD for the same period. The distribution pattern of Fig. 1b is similar to that of Fig. 1a, which means that the standard deviation is also larger over the regions where the mean AOD is higher. Moreover, as shown by the climatological means of wind vectors at $850 \mathrm{hPa}$ and geopotential height in Fig. 1c and d, weak clockwise winds at $850 \mathrm{hPa}$ (Fig. 1c) and flat western flow at $500 \mathrm{hPa}$ (Fig. 1d) suggest that eastern China is dominated by large-scale stable circulation without the frequent disturbances of small-scale weather systems for October. As for vertical structure, Fig. 1e and $\mathrm{f}$ present the height-latitude cross-sections of vertical velocity and divergence of wind respectively. In Fig. 1e, the positive value indicates uniform descending motion over eastern China. Figure $1 \mathrm{f}$ also shows convergence in upper and diver- 
gence in lower altitudes, which are favourable to the maintenance of downward atmospheric motion. Interannually, we show the 10-year distribution of AOD over eastern China in October (spatial distribution in Fig. 2a and regional mean in Fig. 2b).

As indicated by Ziomas et al. (1995) and Xu et al. (2011), in a given season, the anthropogenic emissions are almost constant, while the biomass burning in rural areas may cause a sudden increase in pollution emissions. Consequently, we combine MODIS fire product with NCEP relative humidity, which could influence AOD via light extinction efficiency of aerosols, and wind speed, which may modulate the concentration of aerosols, to explore the interannual variations. As shown in Fig. 2b, the interannual variation of the number of fires in eastern China is weakly correlated with that of AOD. For example, the AOD of 2003 is lower than 2006, but the number of fires is larger. It implies that other factors contributed to the variation of AOD. For the relative humidity, it is around 55\% for all years except 2001 and 2009. Namely, the variation of the relative humidity is not clear. Furthermore, as demonstrated by Twohy et al. (2009), the elevated relative humidity can cause an increase of AOD owing to its impact on hydrophilic aerosols. However, in our data the correlation coefficient between relative humidity and AOD is -0.4 , which did not pass the $90 \%$ confidence level. Differently, the correlation between wind speed and AOD is significant $(-0.63)$ at $95 \%$ confidence level, which indicates that the decrease of AOD value occurs with the increase of wind speed. Based on the above results, it is deduced that the interannual variation of AOD in eastern China, to a certain extent, is determined by the vertical and horizontal movements of air flows, which can influence the spatiotemporal distribution of aerosols.

In order to depict the frequency of pollution events and give the threshold beyond which the value can be regarded as high AOD, we examine the frequency distribution of high AOD ( $>0.5$ and $>0.6)$ as plotted in Fig. 3. Luo et al. (2014) considered the value of AOD $>0.5$ as the big value in China. However, in our data for more than half of eastern China, the frequency of AOD $>0.5$ is larger than $50 \%$ (Fig. 3a). Consequently, we define a more rigorous critical value, 0.6 , as the high AOD threshold. Compared to Fig. 3a, the area with relative high frequency of high AOD with the new threshold reduces in Fig. 3b; for more than $65 \%$ area of eastern China, the frequency of AOD $>0.6$ is under $50 \%$. However, a day is classified into the low-value group if the value of regional mean AOD over the study area is less than 0.4. Xin et al. (2014) investigated the relationships between daily observed $\mathrm{PM}_{2.5}$ (particulate matter with aerodynamic diameters $\leq 2.5 \mu \mathrm{m}$ ) concentration and AOD in northern China, and pointed out that there was a high correlation between the two variables in autumn with a correlation coefficient $\left(R^{2}\right)$ being 0.57 . Therefore, the MODIS AOD is valuable and capable in retrieving the surface $\mathrm{PM}_{2.5}$ concentration. Using the linear regression functions derived by Xin et al. (2014), when
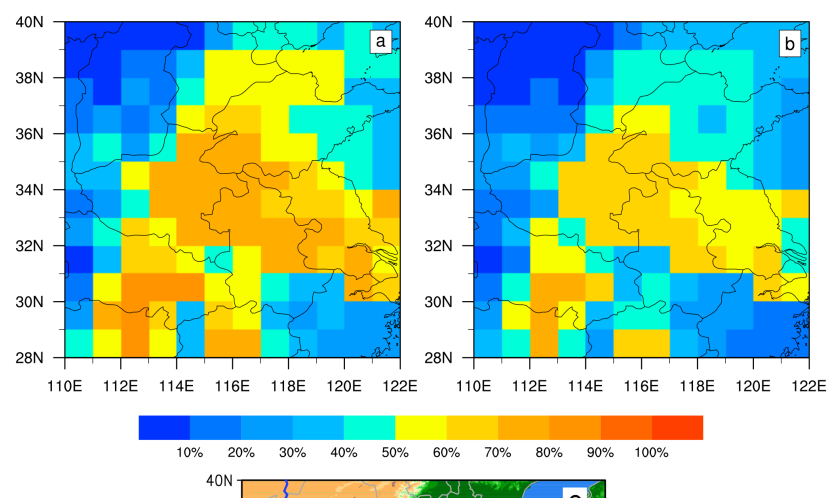

$\begin{array}{lllll}60 \% & 70 \% & 80 \% & 90 \% & 100 \%\end{array}$

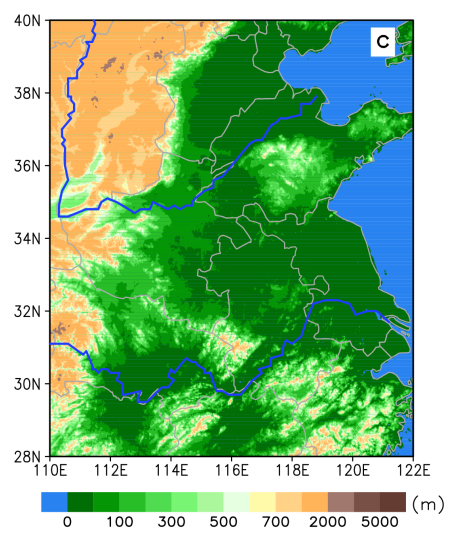

Figure 3. Frequency distribution of (a) $\mathrm{AOD}>0.5$ and (b) AOD > 0.6 in October calculated from 2001 to 2010; (c) the topography of eastern China.

AOD is $0.4(0.6)$, the $\mathrm{PM}_{2.5}$ concentration is calculated to be $72.34 \mu \mathrm{g} \mathrm{m}^{-3}\left(104.62 \mu \mathrm{g} \mathrm{m}^{-3}\right)$. These two values correspond to moderate and lightly polluted in China respectively, supporting our definition of AOD thresholds being suitable. Furthermore, according to the topography shown in Fig. 3c, it is evident that the emergence of high frequency is related closely to the terrain of eastern China. It is noted that the pattern of high frequency distribution in Fig. $3 b$ is consistent with that of high values of 10-year mean AOD distribution in Fig. 1a. High AOD mainly concentrated in plains and hilly areas, especially the economically developed Yangtze River Delta, where it is characterized by dense population along with a great number of industrial and motor vehicle emissions.

Since MODIS AOD represents the aerosol column abundance rather than the content of pollutants near the surface, the upward motion alone (which favours the diffusion of pollution) cannot change the value of AOD. Moreover, the aforementioned two vertical cross-sections illustrate that the climatological mean vertical velocity averaged from 1000 to $100 \mathrm{hPa}$ in autumn over eastern China is downward of $2.56 \times 10^{-2} \mathrm{~Pa} \mathrm{~s}^{-1}$. This suggests that the strong downdraft leads to a more concentrated vertical distribution of pollutants, which gathers pollutants together in the lower layer. As a result, AOD will mainly depend on the divergence of low- 
level wind field in autumn over eastern China. Strong divergence of wind field in the lower troposphere facilitates the diffusion of aerosols, whereas weak divergence favours the formation of poor air quality. As shown in Fig. 1f, the climatological mean divergence, averaged from 1000 to $850 \mathrm{hPa}$, of the lower troposphere is $1.79 \times 10^{-6} \mathrm{~s}^{-1}$.

The relationships among the AOD, vertical velocity and divergence during the study period are shown in Fig. 4a. According to the climatological mean of vertical velocity and the low-level divergence, we divide the samples into four categories: C1, C2, C3 and C4. There are significant differences in vertical velocity and divergence between the distribution of high AOD group and low AOD group. For example, the group with AOD less than 0.4 mainly distributed in $\mathrm{C} 1$, in which both the vertical velocity and the divergence are relative strong. The increasing values of AOD occur with the decreasing values of vertical velocity and divergence of lowlevel winds. The bottom-left corner of the figure is primarily occupied by high AOD group. For a more intuitive representation, Fig. 4b shows a histogram of occurrence frequency for high AOD (>0.6) and low AOD $(<0.4)$ group, which correspond to polluted and clean environments respectively. $\mathrm{C} 1$ presents the maximum frequency of low AOD group, which is nearly $60 \%$. Conversely, pollution exists predominantly in the categories with weak divergence, especially in $\mathrm{C} 3$, where both of two variables are less than the climatological averages. These results are consistent with our hypothesis and confirm that the mean vertical velocity and low-level divergence of winds resulted from diverse synoptic patterns are indicative of regional air quality.

\subsection{Two typical cases: high and low AOD}

On the basis of the above results, two typical cases are presented in this section to show the differences between polluted and clean episodes. The event during 28-31 October 2006 is analysed as a typical HE example, whereas the 4 days from 21 to 24 October 2003 are selected as a typical LE. First of all, we give the number of fires of two cases, which are 18 for HE and 25 for LE accordingly. Since the difference of the sudden enhanced emissions from biomass burning between two cases is small, it can be concluded that AOD difference largely as result of the different atmospheric circulations.

The mean patterns of AOD and atmospheric circulations at the surface, $850,500 \mathrm{hPa}$ in the period of the HE example are given in Fig. 5. The regional averaged AOD of HE was 0.76 , and the maximum value was greater than 1.2 , which signifies a polluted event. The corresponding sea level pressure pattern (Fig. 5b) was almost controlled by uniform pressure field, and the shallow trough promoted west-northwest flow at $500 \mathrm{hPa}$ (Fig. 5d), all of which represented a stable synoptic pattern and was conductive to the storage of air pollutants. In vertical direction, the clear downward motion is in accordance with climatological pattern of autumn
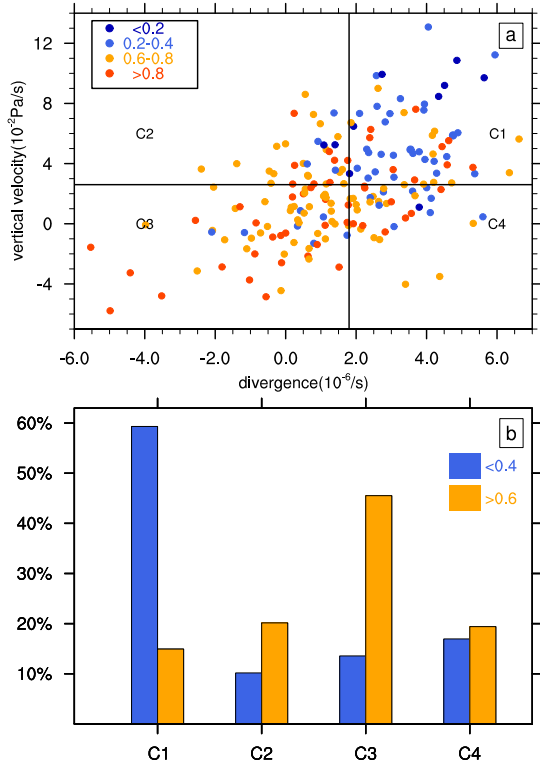

Figure 4. (a) Dependence of AOD on vertical velocity (V: $10^{-2} \mathrm{~Pa} \mathrm{~s}^{-1}$ ) averaged from 1000 to $100 \mathrm{hPa}$ and divergence of wind field (D: $10^{-6} \mathrm{~s}^{-1}$ ) averaged from 1000 to $850 \mathrm{hPa}$. The vertical black line stands for the climatological mean divergence $\left(1.79 \times 10^{-6} \mathrm{~s}^{-1}\right)$ and the horizontal line represents for that of vertical velocity $\left(2.56 \times 10^{-2} \mathrm{Pas}^{-1}\right)$. The samples are divided into four categories according these the two parameters, i.e. C1 $\left(\mathrm{D}>1.79 \times 10^{-6} ; \mathrm{V}>2.56 \times 10^{-2}\right) ; \mathrm{C} 2\left(\mathrm{D}<1.79 \times 10^{-6}\right.$; $\left.\mathrm{V}>2.56 \times 10^{-2}\right) ; \mathrm{C} 3\left(\mathrm{D}<1.79 \times 10^{-6} ; \mathrm{V}<2.56 \times 10^{-2}\right) ; \mathrm{C} 4$ $\left(\mathrm{D}>1.79 \times 10^{-6} ; \mathrm{V}<2.56 \times 10^{-2}\right)$. (b) Frequency distribution of AOD $>0.6$ and AOD $<0.4$ for each category.

(Fig. 5e), and the whole-level averaged value over eastern China is $3.67 \times 10^{-2} \mathrm{~Pa} \mathrm{~s}^{-1}$, leading to an accumulation of aerosols in the low layer. During this period, the main feature of wind filed at $850 \mathrm{hPa}$ was the weak clockwise circulation centred at Shanxi province; wind blew from the north in eastern China under the control of a large-scale anticyclone (Fig. 5c). The divergence of winds in the lower troposphere is $1.62 \times 10^{-6} \mathrm{~s}^{-1}$ for $\mathrm{HE}$ (Fig. 5f), which is less than the climatological mean and does not favour the outflow of air pollutants.

Figure 6 shows the mean patterns for the LE example from 21 to 24 October 2003. Unlike the polluted episode (Fig. 5a) when the whole eastern China was masked by high aerosol loading except a small area in the northwest, the area was mainly dominated by low AOD $(<0.4)$ (Fig. 6a). The mean AOD (0.38) was about half the level that HE case reached. In Fig. 6b, the surface circulation of LE in eastern China was to the front of the high-pressure centre. The temperature and geopotential height in the middle troposphere $(500 \mathrm{hPa})$ indicated a dominant northwesterly flow prevailed over eastern China and led cold air masses to low mid-latitudes (Fig. 6d). Under these conditions, the vertical velocity of $\mathrm{LE}\left(8.05 \times 10^{-2} \mathrm{Pas}^{-1}\right.$, Fig. 6e) is much larger 

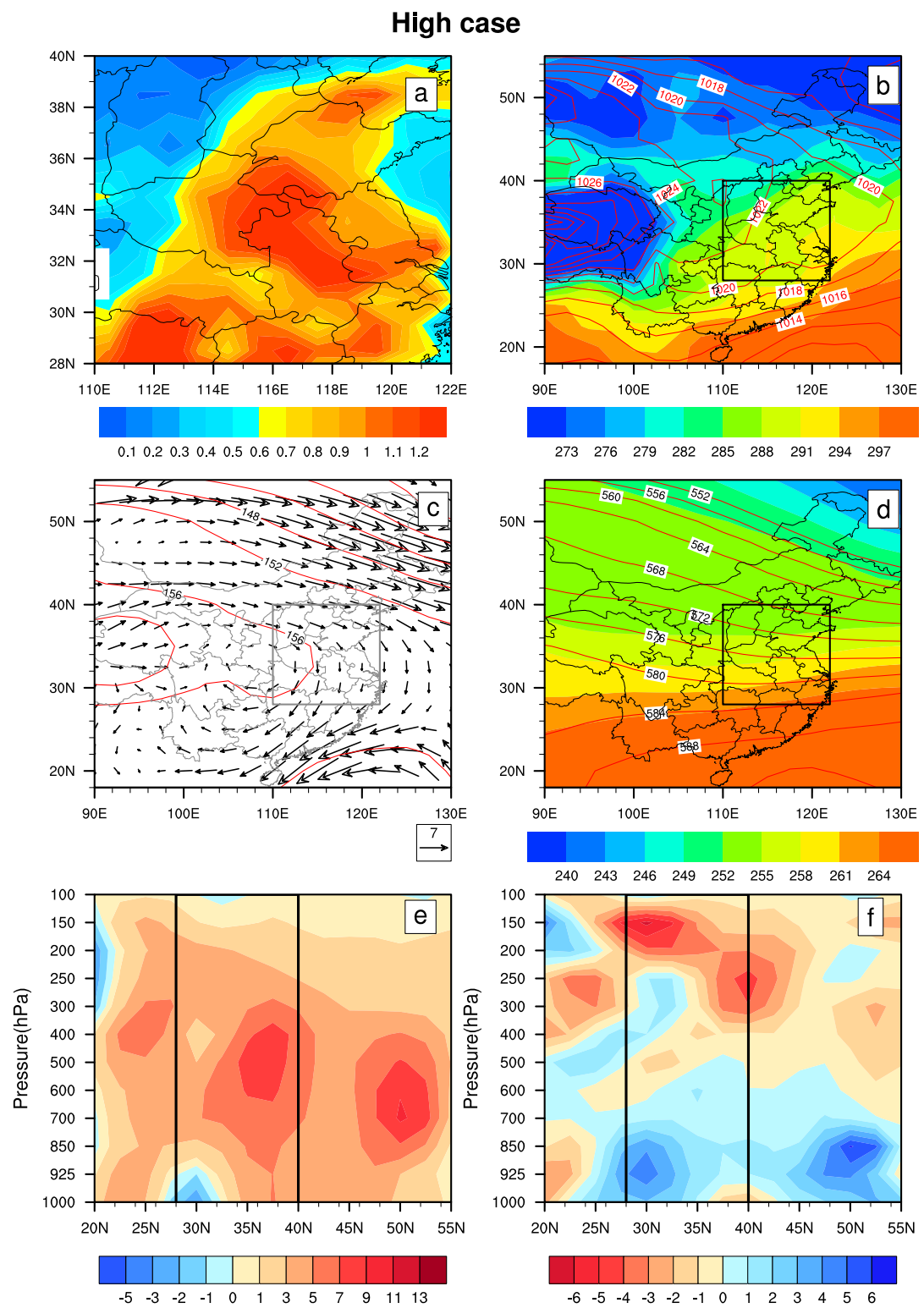

Figure 5. A typical polluted episode (28 to 31 October 2006). (a) The distribution of AOD over eastern China, (b) sea level pressure (red line) and temperature (colour shades) fields, (c) $850 \mathrm{hPa}$ wind and geopotential height (red line) fields, (d) $500 \mathrm{hPa}$ temperature (colour shades) and geopotential height (red line) fields, (e) height-latitude cross-sections of vertical velocity $\left(10^{-2} \mathrm{~Pa} \mathrm{~s}^{-1}\right)$, and (f) divergence of winds $\left(10^{-6} \mathrm{~s}^{-1}\right)$ averaged from longitude of $110-122^{\circ} \mathrm{E}$. Note: black rectangular region represents eastern China $\left(110-122^{\circ} \mathrm{E}, 28-40^{\circ} \mathrm{N}\right)$.

than that of HE over the whole vertical layer, which played an important role in the diffusion of air pollutants when combined with relative strong divergence of winds in the lower troposphere $\left(2.86 \times 10^{-6} \mathrm{~s}^{-1}\right.$, Fig. $\left.6 \mathrm{f}\right)$, being in contrast to the HE case which showed clear distinctions, specifically the weaker downward atmospheric motion and adverse divergent conditions. Moreover, compared to the northerly of $1-4 \mathrm{~m} \mathrm{~s}^{-1}$ in HE episode (Fig. 5c), stronger northwesterly winds of 6-9 $\mathrm{m} \mathrm{s}^{-1}$ were observed at $850 \mathrm{hPa}$ (Fig. 6c) in LE episode.
In addition, to describe different air-mass sources and their transport paths, the HYSPLIT model was applied to the days when the two typical episodes occurred. For each day, we calculated the backward trajectories originated from three locations and the associated ending height is $1000 \mathrm{~m}$ above ground level. Trajectories were considered to be initiated at 02:00 (universal time coordinated) when Terra/MODIS passes across China, terminating at the end of $48 \mathrm{~h}$. As shown in Fig. 7, the backward trajectories of 4 polluted days (Fig. 7a) were composed of short tracks, which were mainly trapped in eastern China. This indicated that the pollution 

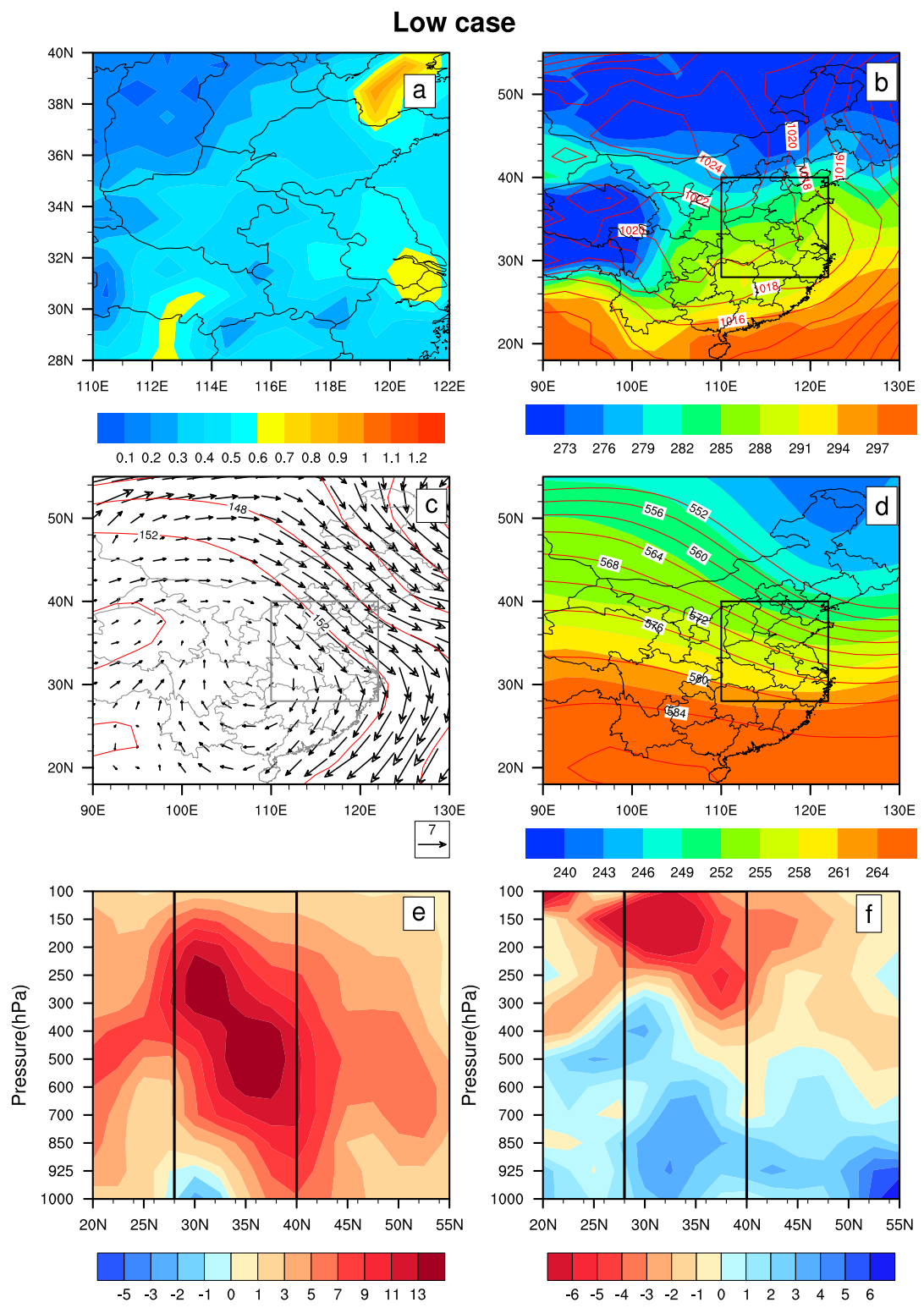

Figure 6. As in Fig. 5 but for the clean episode (21-24 October 2003).

was caused by the combination of the circulation pattern, which acted against dissipation of air pollutants, and a great deal of local emissions in the studied area. In contrast, the LE episode presents a cluster of relatively longer trajectories corresponded to fast-moving air masses from Mongolia. Northwesterly cold winds on these days dispersed local air pollutants and also brought in clean air.

\subsection{All selected cases}

The aforementioned case studies show that without considering the variations in emission some synoptic types are favourable to the occurrence of the air pollution while others are not. Comprehensive statistics of all cases in the study pe- riod over eastern China are calculated. Excluding all missing and moderate AOD days, a total 120 days are extracted for the research, of which there are 90 days with high AOD and 30 days with low AOD. Tables 1 and 2 list the statistical results for the 18 pollution and 10 clean episodes respectively.

It is found from Table 1 that 2002 and 2006 are both years with the maximum occurrence (16 days) of pollution, which is consistent with the high value presented in Fig. 2. The estimated durations of polluted episodes, on a daily basis, mostly last for about 4 days or longer. To be more specific, for sea level pressure field the most frequent pattern is characterized as the periphery of the high-pressure centred in the Tibetan plateau or Mongolia, which amounts to 38 days. The uniform pressure over eastern China is the second high-frequency 

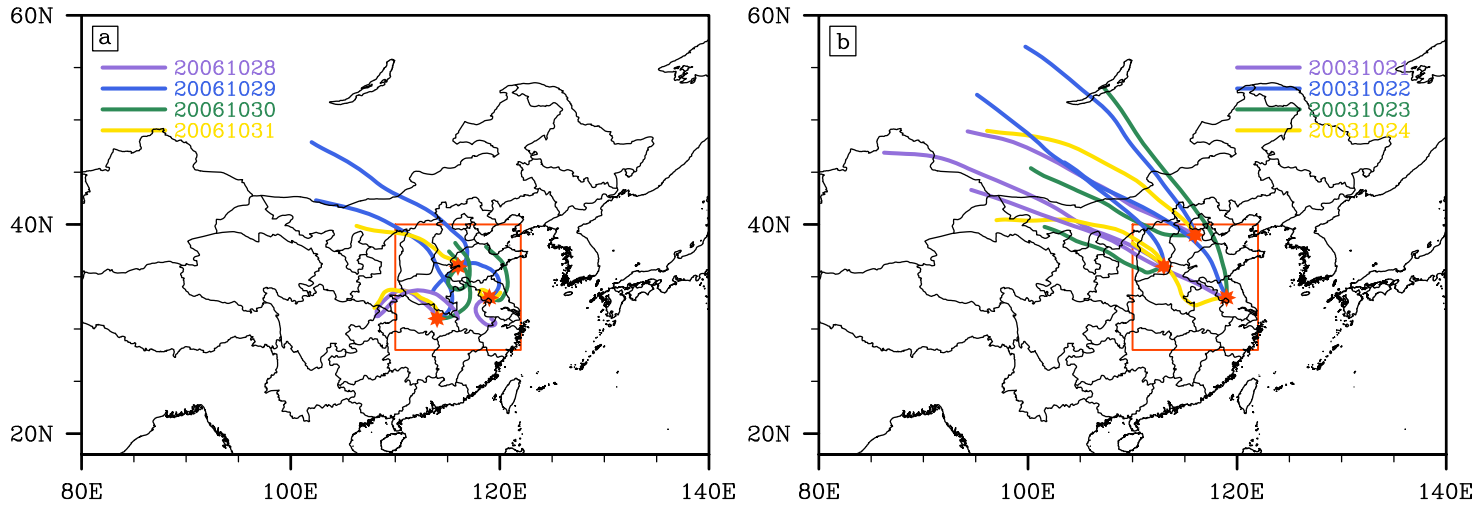

Figure 7. The $48 \mathrm{~h}$ backward trajectories for two episodes over eastern China (red box); the three red stars represent three ending points. (a) Polluted episode at $31^{\circ} \mathrm{N}, 114^{\circ} \mathrm{E} ; 33^{\circ} \mathrm{N}, 119^{\circ} \mathrm{E} ; 36^{\circ} \mathrm{N}, 116^{\circ} \mathrm{E}$. (b) Clean episode at $33^{\circ} \mathrm{N}, 119^{\circ} \mathrm{E} ; 36^{\circ} \mathrm{N}, 113^{\circ} \mathrm{E} ; 39^{\circ} \mathrm{N}, 116^{\circ} \mathrm{E}$.

Table 1. Descriptions of observed meteorological field features for the 18 polluted episodes. The rows in the table with same capital letters in the parentheses indicate those episodes are affected by similar circulation patterns in all the three atmospheric levels.

\begin{tabular}{|c|c|c|c|c|}
\hline Episodes & Year (date) & Surface & $850 \mathrm{hPa}$ & $500 \mathrm{hPa}$ \\
\hline 1(A) & 2002 (1-4 Oct) & Before the passage of a cold front & strong cold wind blow to south & NW flow \\
\hline 2(B) & $2002(8-16$ Oct $)$ & Uniform pressure field & the rear of the anticyclone & W-NW flow \\
\hline $3(\mathrm{C})$ & 2002 (24-26 Oct) & $\begin{array}{l}\text { Periphery of the high-pressure system } \\
\text { centred in Mongolia }\end{array}$ & the foreside of the anticyclone & $\begin{array}{l}\text { NW flow (behind } \\
\text { the trough) }\end{array}$ \\
\hline $4(\mathrm{C})$ & 2004 (7-13 Oct) & $\begin{array}{l}\text { Periphery of the high-pressure system } \\
\text { centred in Mongolia }\end{array}$ & the foreside of the anticyclone & $\begin{array}{l}\text { NW flow (behind } \\
\text { the trough) }\end{array}$ \\
\hline 5(D) & 2004 (18-22 Oct) & $\begin{array}{l}\text { Periphery of the high-pressure system } \\
\text { centred in the TP }\end{array}$ & anticyclonic circulation & W flow \\
\hline $6(F)$ & 2004 (27-29 Oct) & Rear of the high-pressure system & south wind & SW flow \\
\hline 7(D) & 2005 (16-18 Oct) & $\begin{array}{l}\text { Periphery of the high-pressure system } \\
\text { centred in the TP }\end{array}$ & anticyclonic circulation & shallow trough \\
\hline $8(\mathrm{E})$ & 2005 (23-26 Oct) & Rear of the high-pressure system & the rear of the anticyclone & W-NW flow \\
\hline $9(\mathrm{~B})$ & $2006(4-15$ Oct $)$ & Uniform pressure field & the rear of the anticyclone & W-NW flow \\
\hline 10(D) & 2006 (28-31 Oct) & $\begin{array}{l}\text { Periphery of the high-pressure system } \\
\text { centred in the TP }\end{array}$ & the foreside of the anticyclone & shallow trough \\
\hline 11(B) & 2007 (16-25 Oct) & Uniform pressure field & anticyclonic circulation & W-NW flow \\
\hline $12(\mathrm{~B})$ & $2008(1-3$ Oct $)$ & Uniform pressure field & the rear of the anticyclone & NW flow \\
\hline $13(\mathrm{E})$ & 2008 (13-17 Oct) & Rear of the high-pressure system & the rear of the anticyclone & W-NW flow \\
\hline $14(\mathrm{C})$ & 2009 (2-6 Oct) & $\begin{array}{l}\text { Periphery of the high-pressure system } \\
\text { centred in Mongolia }\end{array}$ & the foreside of the anticyclone & $\begin{array}{l}\text { NW flow (behind } \\
\text { the trough) }\end{array}$ \\
\hline $15(\mathrm{~A})$ & 2009 (15-16 Oct) & Before the passage of a cold front & strong cold flow toward south & NW flow \\
\hline $16(\mathrm{D})$ & 2009 (21-25 Oct) & $\begin{array}{l}\text { Periphery of the high-pressure system } \\
\text { centred in the TP }\end{array}$ & anticyclonic circulation & W flow \\
\hline $17(\mathrm{~B})$ & 2010 (16-17 Oct) & $\begin{array}{l}\text { Periphery of the high-pressure system } \\
\text { centred in Mongolia }\end{array}$ & the rear of the anticyclone & NW flow \\
\hline $18(\mathrm{C})$ & $2010(28-31$ Oct $)$ & $\begin{array}{l}\text { Periphery of the high-pressure system } \\
\text { centred in Mongolia }\end{array}$ & the foreside of the anticyclone & $\begin{array}{l}\text { NW flow (behind } \\
\text { the trough) }\end{array}$ \\
\hline
\end{tabular}

type with a percentage of $37 \%$, namely 34 days. Among the remaining three types, one is interpreted as the pattern before the passage of a cold front. The corresponding pattern in the lower troposphere $(850 \mathrm{hPa})$ is characterized as strong cold air flow moving toward eastern China, which involves two episodes (6 days). The other 15 episodes are dominated by the anticyclonic circulation in $850 \mathrm{hPa}$. It is noted that the region is controlled by different parts of anticyclones. The frequency of the rear of the anticyclone is 35 days, while the frequency of the foreside and the centre of the anticyclone are both 23 days. For the patterns of $500 \mathrm{hPa}$ geopotential height, there are 30 days influenced by the northwest flow, of which 25 days were caused by the upper air trough. The number of days associated with the west-northwest flow and 
Type 01
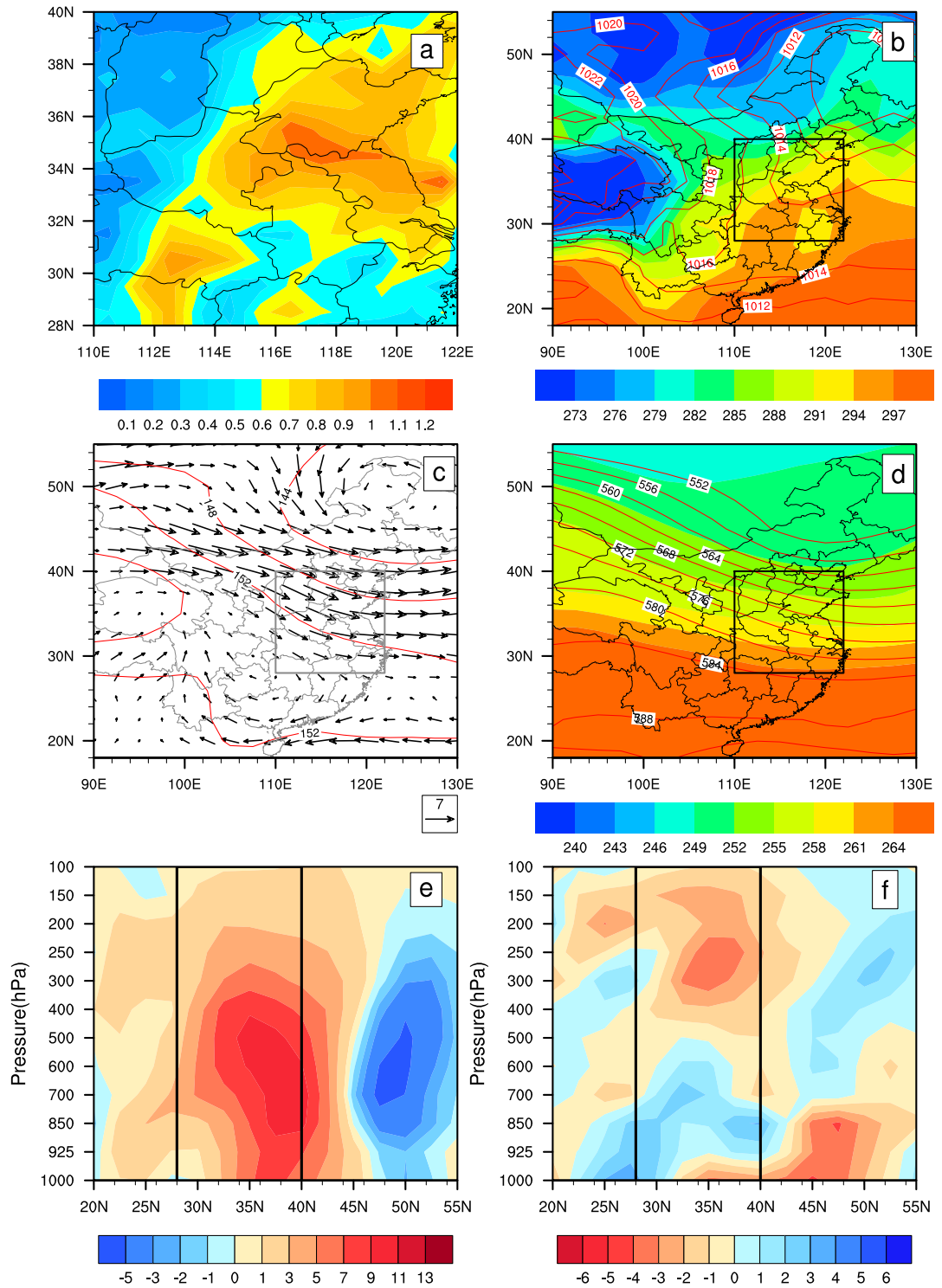

Figure 8. Type 1 (polluted). (a) The distribution of AOD over eastern China, (b) sea level pressure (red line) and temperature (colour shades) fields, (c) $850 \mathrm{hPa}$ wind field and geopotential height (red line) fields, (d) $500 \mathrm{hPa}$ temperature (colour shades) and geopotential height (red line) fields, (e) height-latitude cross-sections of vertical velocity $\left(10^{-2} \mathrm{~Pa} \mathrm{~s}^{-1}\right)$, and (f) divergence of winds $\left(10^{-6} \mathrm{~s}^{-1}\right)$ averaged from longitude of $110-122^{\circ} \mathrm{E}$. Note: black rectangular region represents eastern China $\left(110-122^{\circ} \mathrm{E}, 28-40^{\circ} \mathrm{N}\right)$.

west flow is 19 and 7 respectively. In addition, the southwest flow prevailed during a 3-day episode.

Table 2 is the same as Table 1 but for 10 clean episodes. Precipitation is an important mechanism of aerosol removal, which may compromise the estimation of effects due to the circulation patterns. In this study, only one episode is identified as the passage of cold front (23-26 October 2008), which is accompanied by significant rainfall. There is no occurrence of large-scale precipitation during any other episodes, even on the day before the episodes and during consecutive days following the episodes. The regional mean value of clean episodes that with precipitation is only about $1 \mathrm{~mm} \mathrm{day}^{-1}$, which is equivalent to that of polluted episodes. Therefore, it does not influence the results of our study. According to Table 2, the number of low-value day peak in 2003. The surface high-pressure centred in the northwest of China is the frequent pattern, accounting for 14 of the total 30 clean days. Additionally, there are 8 days corresponding to the passage of a cold front, followed by a frequency of 5 days for the rear of a high-pressure system over the Yellow Sea. The remaining 3 days are characterized by a uniform pressure field. For $850 \mathrm{hPa}$ wind fields, the pattern dominated by anticy- 
Table 2. As in Table 1 but for 10 clean episodes.

\begin{tabular}{|c|c|c|c|c|}
\hline Episodes & Year (date) & Surface & $850 \mathrm{hPa}$ & $500 \mathrm{hPa}$ \\
\hline $1(\mathrm{G})$ & $2001(10-11$ Oct $)$ & Periphery of the high-pressure system & anticyclonic circulation & $\begin{array}{l}\text { NW flow (behind } \\
\text { the trough) }\end{array}$ \\
\hline $2(\mathrm{H})$ & $2001(29-30$ Oct $)$ & Rear of the high-pressure system & anticyclonic circulation & W flow \\
\hline $3(\mathrm{G})$ & 2003 (15-18 Oct) & Periphery of the high-pressure system & $\begin{array}{l}\text { the foreside of the anticyclone, strong } \\
\text { wind }\end{array}$ & NW flow \\
\hline $4(\mathrm{G})$ & 2003 (21-24 Oct) & Periphery of the high-pressure system & $\begin{array}{l}\text { the foreside of the anticyclone, strong } \\
\text { wind }\end{array}$ & NW flow \\
\hline $5(\mathrm{G})$ & 2003 (27-28 Oct) & Periphery of the high-pressure system & $\begin{array}{l}\text { the foreside of the anticyclone, strong } \\
\text { wind }\end{array}$ & NW flow \\
\hline $6(\mathrm{G})$ & 2004 (2-4 Oct) & Uniform pressure field & anticyclonic circulation & $\begin{array}{l}\text { NW flow (behind } \\
\text { the trough) }\end{array}$ \\
\hline $7(\mathrm{H})$ & 2005 (8-10 Oct) & Rear of the high-pressure system & anticyclonic circulation & W flow \\
\hline $8(\mathrm{I})$ & 2008 (23-26 Oct) & Passage of the cold front & strong cold wind & NW flow \\
\hline $9(\mathrm{I})$ & 2009 (17-20 Oct) & Passage of the cold front & strong cold wind & NW flow \\
\hline $10(\mathrm{G})$ & 2010 (3-4 Oct) & Periphery of the high-pressure system & anticyclonic circulation, strong wind & $\begin{array}{l}\text { NW flow (behind } \\
\text { the trough) }\end{array}$ \\
\hline
\end{tabular}

clonic wind vectors over the study area has the highest frequency of 12 days. The second frequent pattern is the anterior part of the anticyclone (10 days), and the remaining two episodes are related to the cold front bringing strong and cold airs southwardly into eastern China in the lower troposphere. The $500 \mathrm{hPa}$ geopotential heights of clean episodes, unlike those for polluted episodes, include only two dominant airflow directions. For most of clean days, the northwest flow prevails, whereas the other 5 days are associated with flat west streams.

The characteristics of circulation patterns of all polluted and clean episodes at each level are gained through the above statistics. In terms of a single level (surface $/ 850 \mathrm{hPa} / 500 \mathrm{hPa}$ ), the circulation patterns for different episodes are similar to each other. However, it is the combination of circulations at the lower and upper levels that the air quality always depends on. The rows in Tables 1 and 2 with same capital letters in the parentheses following the sequence number indicate those episodes are affected by the similar circulation patterns in all the three atmospheric levels. There are nine different letters in two tables, namely the entire 28 episodes are classified into nine different types, among which there are six polluted types and three clean types.

\subsection{Statistics and synthetic analysis}

Based on the above results of all cases, nine types are inspected in detail in this section. Before the description of each type, it is pointed out that the mean AOD and meteorological fields for each type, which consist of the sea level pressure, the surface temperature, the $850 \mathrm{hPa}$ wind and geopotential height, the $500 \mathrm{hPa}$ geopotential height and temperature, the vertical velocity and the wind divergence, are averaged for the several episodes that are marked with the same letters in Table 1 (Table 2). The percentage of each polluted (clean) type is calculated on a daily basis. More specifically, Figs. 8 to 13 present the spatial distribution of mean AOD for six high-value types and the associated large-scale three-dimensional atmospheric circulation structure. Each type contains a set of three different layers, which differ from each other, either in terms of the position and intensity of weather systems or in the vertical allocation of the corresponding atmospheric circulations.

Firstly, the two episodes marked with the letter A in Table 1 are classified as Type 1, which account for $6.7 \%$ of all polluted days. Distribution of AOD is shown in Fig. 8a; high AOD value appears in Anhui province and the regional mean AOD is 0.60 . The corresponding atmospheric circulations are shown in Fig. 8b-d. In detail, the sea level pressure field is characterized as the pattern before the passage of a cold front. Before the arrival of the cold flow associated with a low-pressure system over northeast of China, warm air mass accumulates ahead of the front, which favours the increase of pollutants. At the higher levels, the area is situated behind the trough, and thus the dominant wind direction in the east is northwest, which gradually leads cold air mixed with northern pollutants toward eastern China. Even though the vertical downward motion is strong $\left(5.13 \times 10^{-2} \mathrm{~Pa} \mathrm{~s}^{-1}\right)$, the divergence of winds in the lower troposphere is weak $\left(0.49 \times 10^{-6} \mathrm{~s}^{-1}\right)$. In fact, a convergence of air at $850 \mathrm{hPa}$ can be seen in Fig. 8c, whereas the wind speed is relatively high. In view of the above-mentioned facts, the pollution of this type is not quite serious.

Type 2 (marked with the letter B) is the most frequent among the six polluted types with a percentage of $40 \%$. It is evident that the occurrence of pollution in eastern China mainly requires a uniform pressure field over the surface (Fig. 9). At $850 \mathrm{hPa}$, the pattern corresponds to weak souther- 


\section{Type 02}
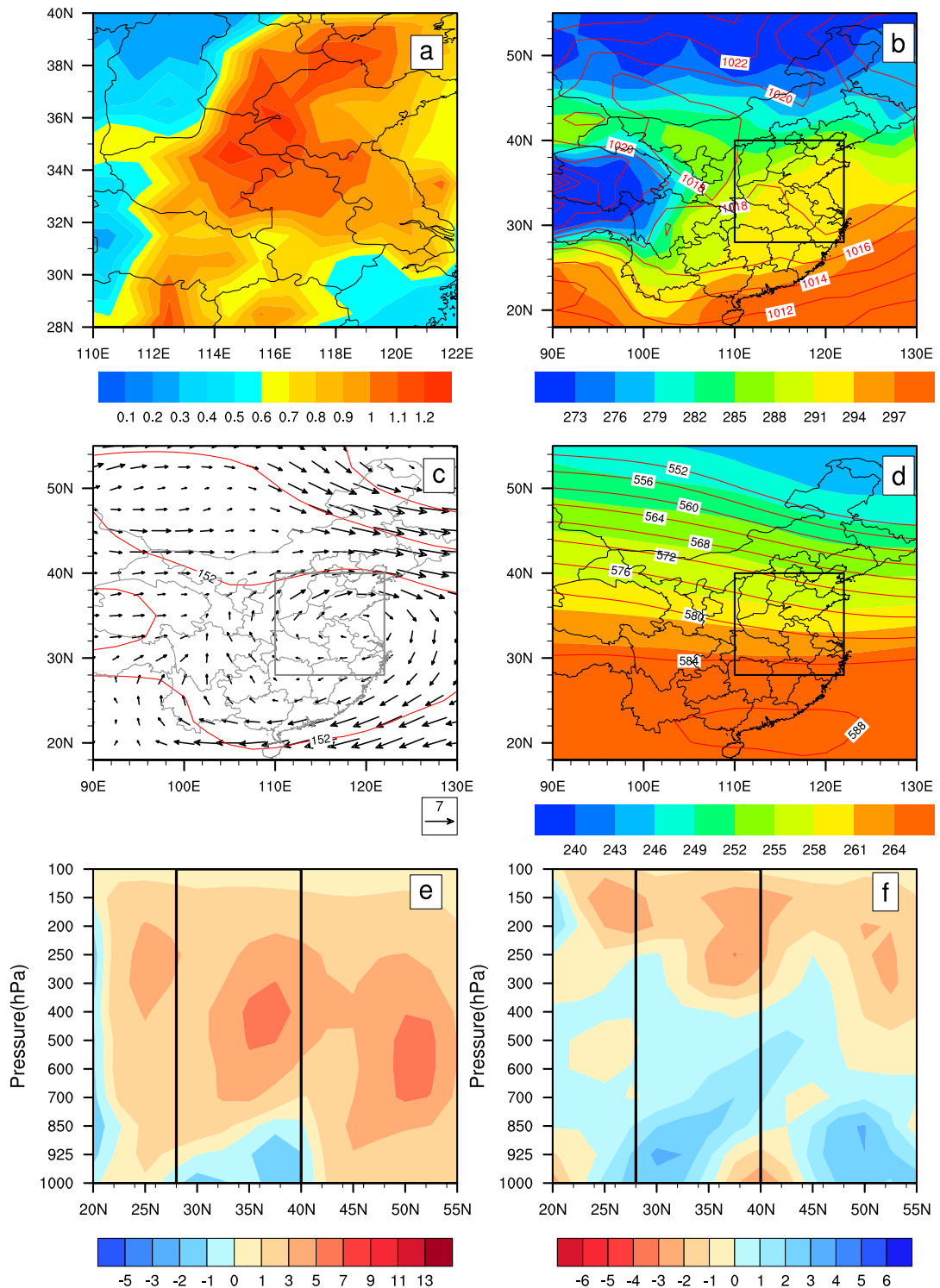

Figure 9. As in Fig. 8 but for Type 2 (polluted).

lies controlled by the rear sector of an anticyclonic circulation. Additionally, the upper-level west-northwest flow is crossing the area. Under those fair weather conditions, both the vertical velocity $\left(1.97 \times 10^{-2} \mathrm{~Pa} \mathrm{~s}^{-1}\right)$ and the divergence $\left(0.97 \times 10^{-6} \mathrm{~s}^{-1}\right.$ for the lower troposphere and $1.08 \times 10^{-6} \mathrm{~s}^{-1}$ for the middle level) for Type 2 are less than the climatological mean mentioned earlier, allowing the stagnation of pollutants. According to Table 1, it seems that Type 2 can last for a long time. Generally speaking, Type 2 is a relatively stable and serious pollution example with a mean AOD value of 0.77 .

Type 3 (marked with the letter $\mathrm{C}$ ) is associated with four episodes, accounting for $21.1 \%$. From Fig. 10a, high AOD values centre in Henan province, extending to the southeast and southwest. The corresponding circulation structure is shown in Fig. 10b-d. Over the surface, the region is governed by the periphery of a high-pressure system located in Mongolia, which results in low-pressure gradient over the central of eastern China. At $500 \mathrm{hpa}$, an upper air trough causes moderate northeasterly flows. The wind field in the lower troposphere can be considered as an anticyclone, and the wind direction is consistent with the diffusion direction of pollutants. From Fig. 10e, the strong descending motion dominates, which is $4.91 \times 10^{-2} \mathrm{~Pa} \mathrm{~s}^{-1}$. However, the limited low-level speed and divergence of winds $\left(1.54 \times 10^{-6} \mathrm{~s}^{-1}\right)$, prevent the spread of pollutants to outside the area. These conditions yield a regional averaged AOD value of 0.61. 


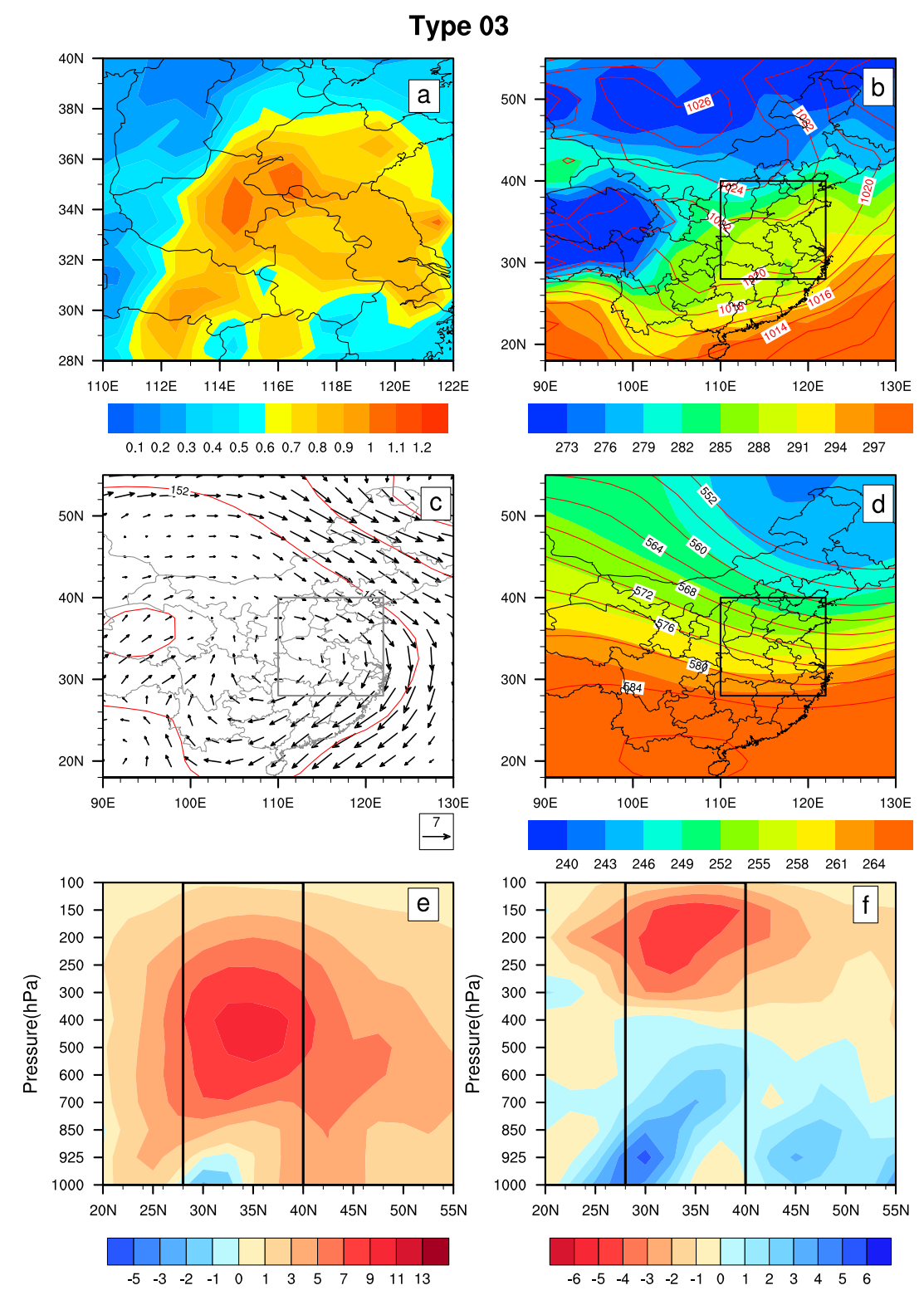

Figure 10. As in Fig. 8 but for Type 3 (polluted).

Type 4 (marked with the letter D) consists of four polluted episodes (accounts for $18.9 \%$ ), which all lasted for 3 to 5 days. It resembles Type 2 concerning the spatial distribution of AOD (Fig. 11a), although the contamination degree of Type 4 is relatively light, and the mean AOD is 0.63 . Over the surface (Fig. 11b), the pattern is characterized by the periphery of a high barometric system over Tibetan Plateau. The lack of pressure gradient allows for formation of pollution. At $850 \mathrm{hPa}$ (Fig. 11c), an anticyclone centred over the study area results in moderate to low wind speed. In the middle troposphere the circulation is almost zonal, passing through mid-latitudes (Fig. 11d). Compared to Type 2, the vertical velocity and the divergence, shown in Fig. 11e and f over eastern China respectively, are stronger. Nevertheless, it should be noted that low-level averaged divergence is weaker than that of climatological mean, which are probably the reason why the mean AOD of Type 4 is less than Type 2.

Type 5 (marked with the letter E) depicts a different pattern of pollution distribution. As shown in Fig. 12a, the pollutants for Type 5 are gathered in the northeast rather than the centre of the studied area. Because the pollutants are not widespread, the regional mean AOD reaches a mere 0.60 . Figure 12 represents the associated circulations. On both the surface and the $850 \mathrm{hPa}$ level, eastern China is found in the rear zone of the high-pressure system located in eastern ocean. Southerly wind dominates in the lower troposphere, while in the middle troposphere, the sparse isopleths indicate small geopotential height gradient. Owing to the weakness 
Type 04
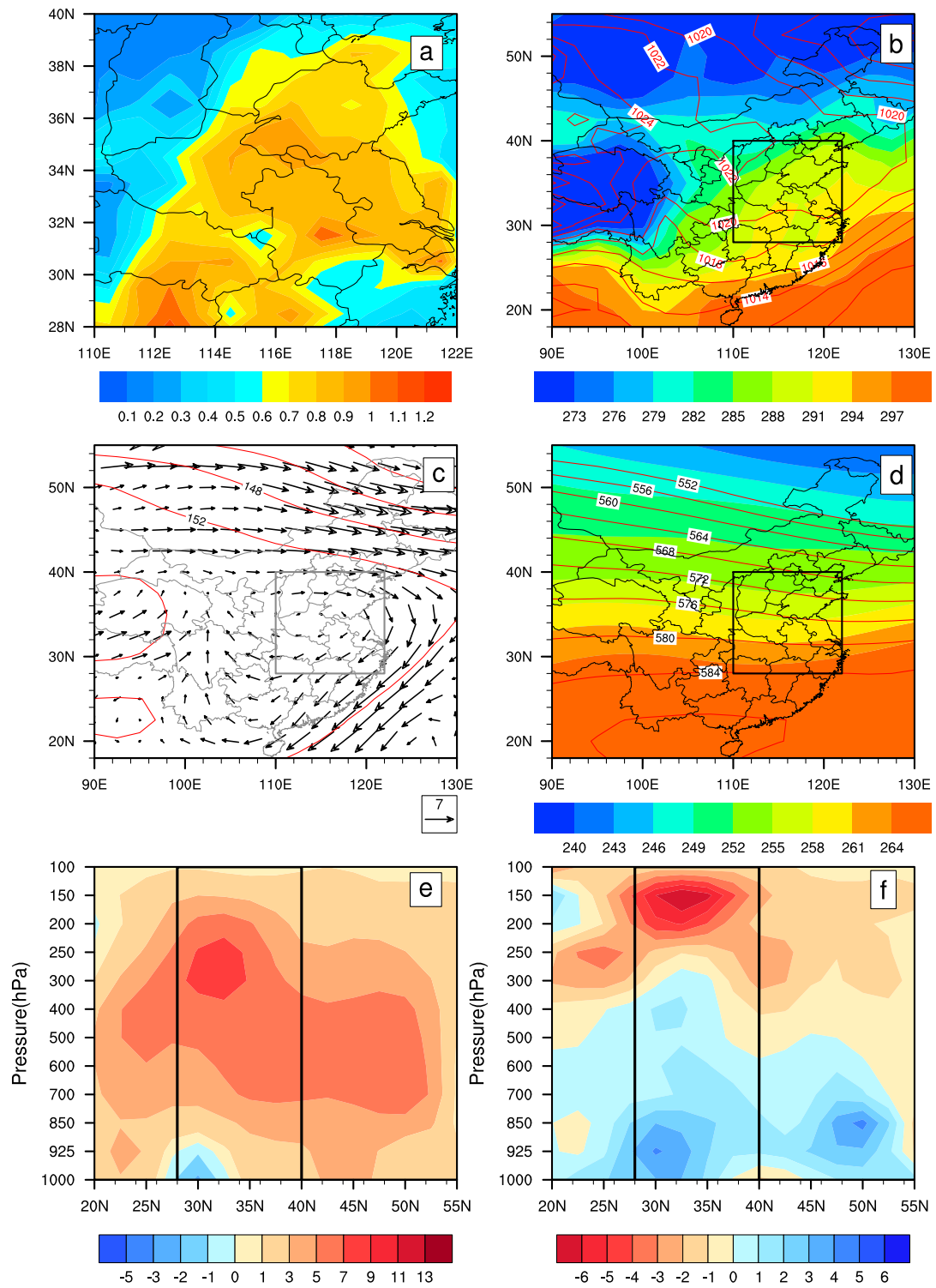

Figure 11. As in Fig. 8 but for Type 4 (polluted).

in vertical motion $\left(2.21 \times 10^{-2} \mathrm{~Pa} \mathrm{~s}^{-1}\right)$ and also in the divergence of winds $\left(1.64 \times 10^{-6} \mathrm{~s}^{-1}\right)$ under such calm weather conditions, pollution is formed. This type occurred for $10 \%$ of all polluted days in the sample.

Type 6 (marked with the letter F) consists of only one 3day episode (accounts for $3.3 \%$ ). Very high AOD values are found in Hunan province, and the averaged AOD over the whole area is 0.70 . A surface high-pressure system is centred over the Yellow Sea, resulting in southerly flow over eastern China, which prevails in the lower troposphere. These conditions contribute to the northward extension of pollutants (Fig. 13a). As shown in Fig. 13e, the vertical velocity pattern is different from that of other weather types. The descend- ing motion prevails in the higher troposphere, while the ascending motion dominates in the lower troposphere, transporting some pollutants to higher levels. Consequently, we consider the divergence at both the lower and middle troposphere that are presented in Fig. 13f. Despite the divergence of low level is $2.63 \times 10^{-6} \mathrm{~s}^{-1}$, the corresponding value of the middle troposphere is merely $0.72 \times 10^{-6} \mathrm{~s}^{-1}$. Thereby, the column AOD is large. Type 6 is usually identified as a "southerly type".

Similar to the polluted episodes, the results for clean episodes are detailed in the following. The distributions of AOD and the corresponding weather maps for clean types are shown in Figs. 14-16. 
Type 05
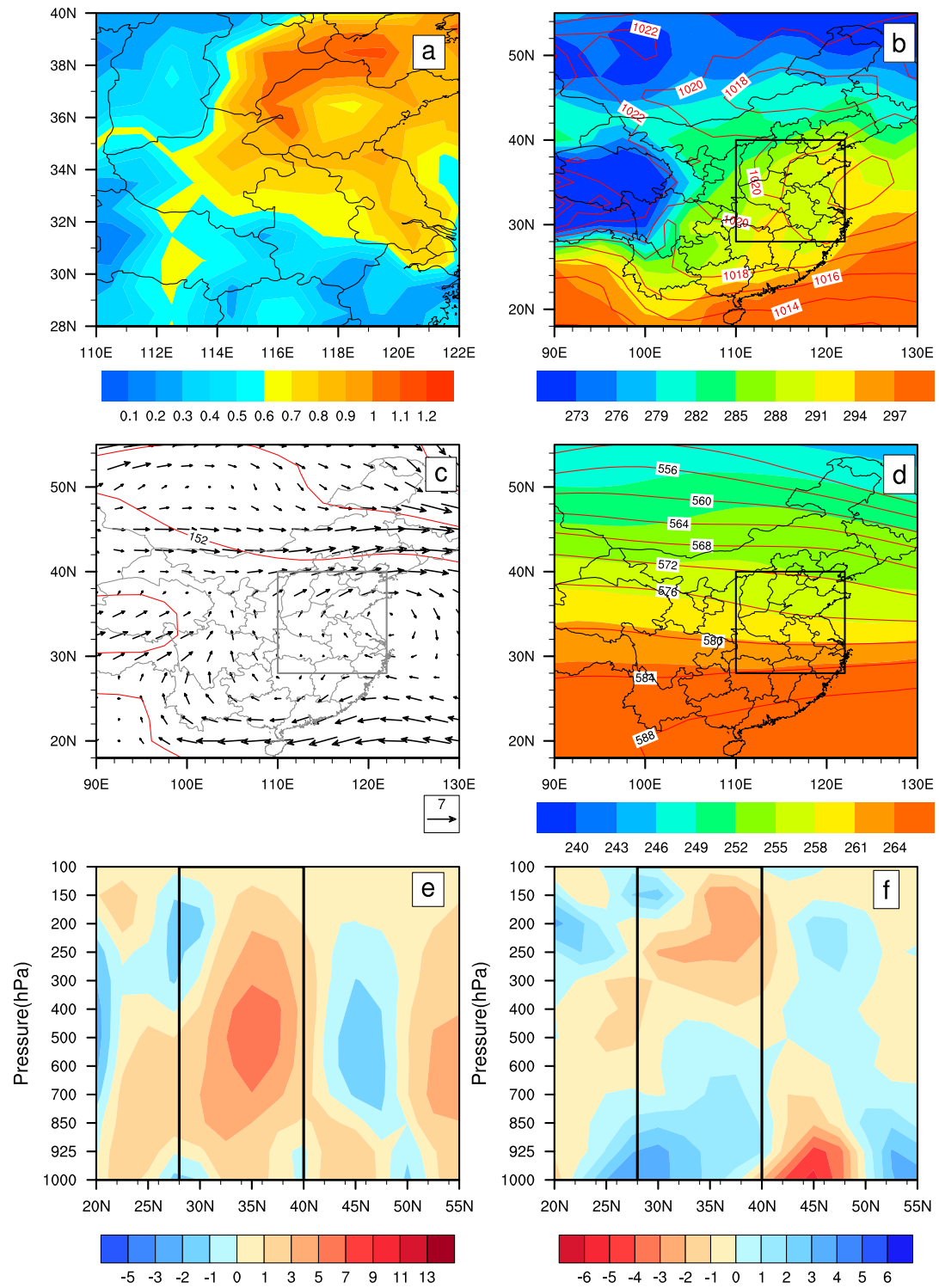

Figure 12. As in Fig. 8 but for Type 5 (polluted).

Type 7 (marked with the letter $G$ ) is the most frequent clean type during the whole examined low-value days (accounts for $57.6 \%$ ). As shown in Fig. 14a, the maximum AOD is less than 0.6. In addition, the mean AOD for the entire region is 0.33 , which represents improved air quality in contrast with the above polluted types. According to the circulation pattern of Type 7 (Fig. 14), over the surface, cold air moves toward eastern China continually in front of the high barometric system located in Inner Mongolia. A trough appears in the upper atmosphere, accompanied by an anticyclonic eddy in the lower troposphere, which causes strong northwesterly winds (Fig. 14c and d) in the area. When considering the vertical structure of Type 7 , as shown in LE, uniformly downward motion with the vertical velocity of $5.78 \times 10^{-2} \mathrm{~Pa} \mathrm{~s}^{-1}$ prevails. Therefore, strong divergence $\left(2.93 \times 10^{-6} \mathrm{~s}^{-1}\right)$ resulted from wind field in the lower troposphere facilitates the removal of the accumulated pollutants from local areas.

Type 8 (marked with the letter $\mathrm{H}$ ), which accounts for $18.2 \%$ of all clean days, is characterized by a circulation at the rear of weak high-pressure system centred in the east coast of China (Fig. 15). Corresponding to the pattern over the surface, anticyclonic circulations are observed at $850 \mathrm{hPa}$. The vertical downward motion $\left(2.65 \times 10^{-2} \mathrm{~Pa} \mathrm{~s}^{-1}\right)$ in eastern China is somewhat stronger than that of climatological mean, whereas the divergence $\left(3.60 \times 10^{-6} \mathrm{~s}^{-1}\right)$ is much larger than the 10-year average, blowing away local pollu- 


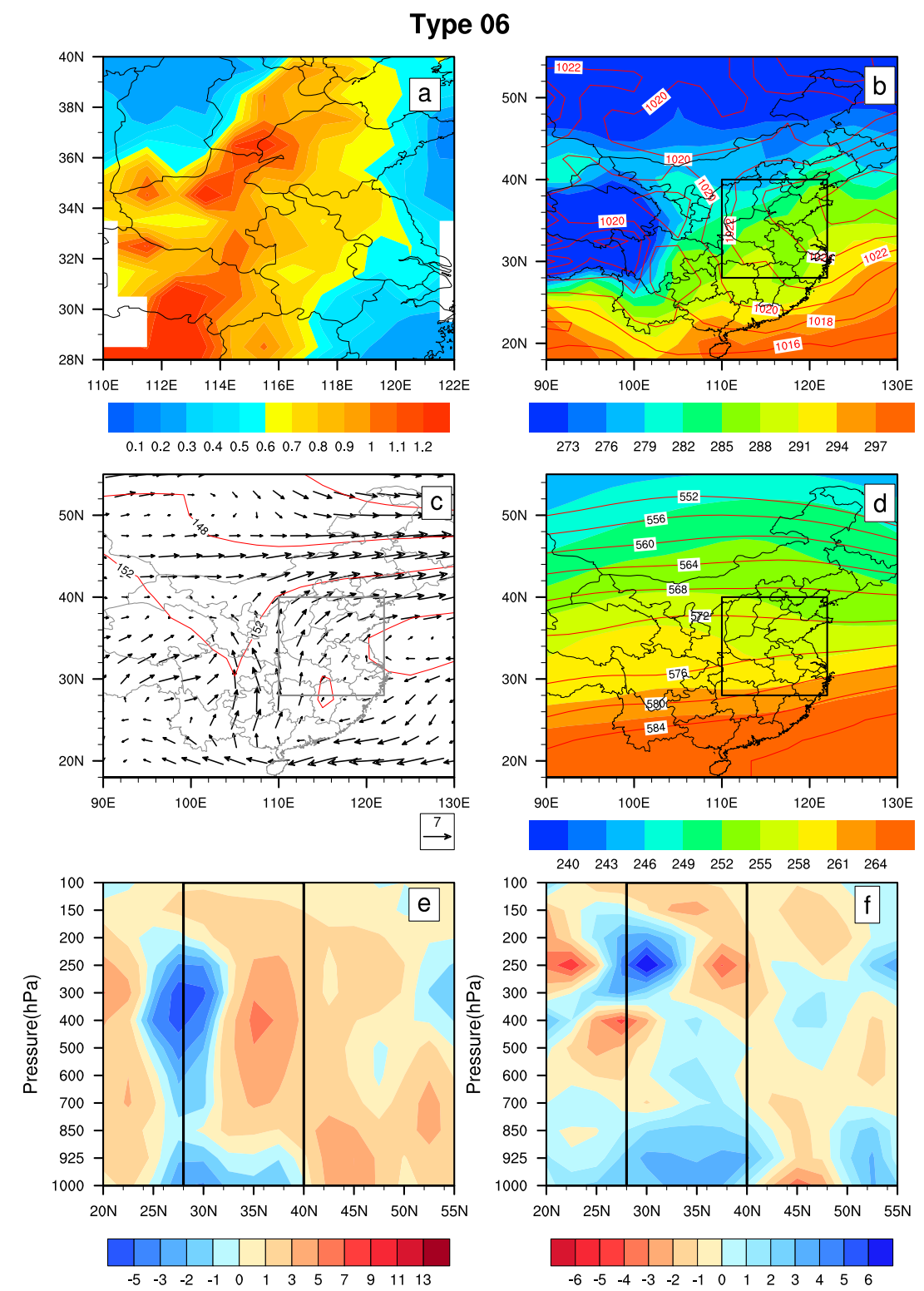

Figure 13. As in Fig. 8 but for Type 6 (polluted).

tants and bringing clean air from the sea to the region. The above conditions induce a lower mean AOD value of 0.35 .

Type 9 (marked with the letter I) is the cleanest type with an averaged AOD value of 0.31 . It is associated with the passage of a cold front, and the occurrence frequency is $24.2 \%$. Over the surface, the high-pressure system over the northwest of China, along with a low-pressure system centred in the northeast of China, intensifies the southward flow of cold air masses, as can be seen in Fig. 16. In the lower troposphere, strong northwesterly winds prevail in the region, and the dense isopleths representing strong geopotential height gradient appear in the middle troposphere. The strong descending motion $\left(6.81 \times 10^{-6} \mathrm{~s}^{-1}\right)$ is associated with the whole vertical layers of atmosphere while favourable diffu- sion condition at the low layer is shown in Fig. 16f. The advection of cold and dry air from northwest contributes to the good air quality.

In addition, from the above analyses, it can be seen that the temperature fields are particularly indicative of the movement and the intersection of warm and cold air flows. Since the large-scale temperature distribution is closely related to the atmospheric circulations, the detailed relationship between AOD and temperature needs further investigation in the future. 

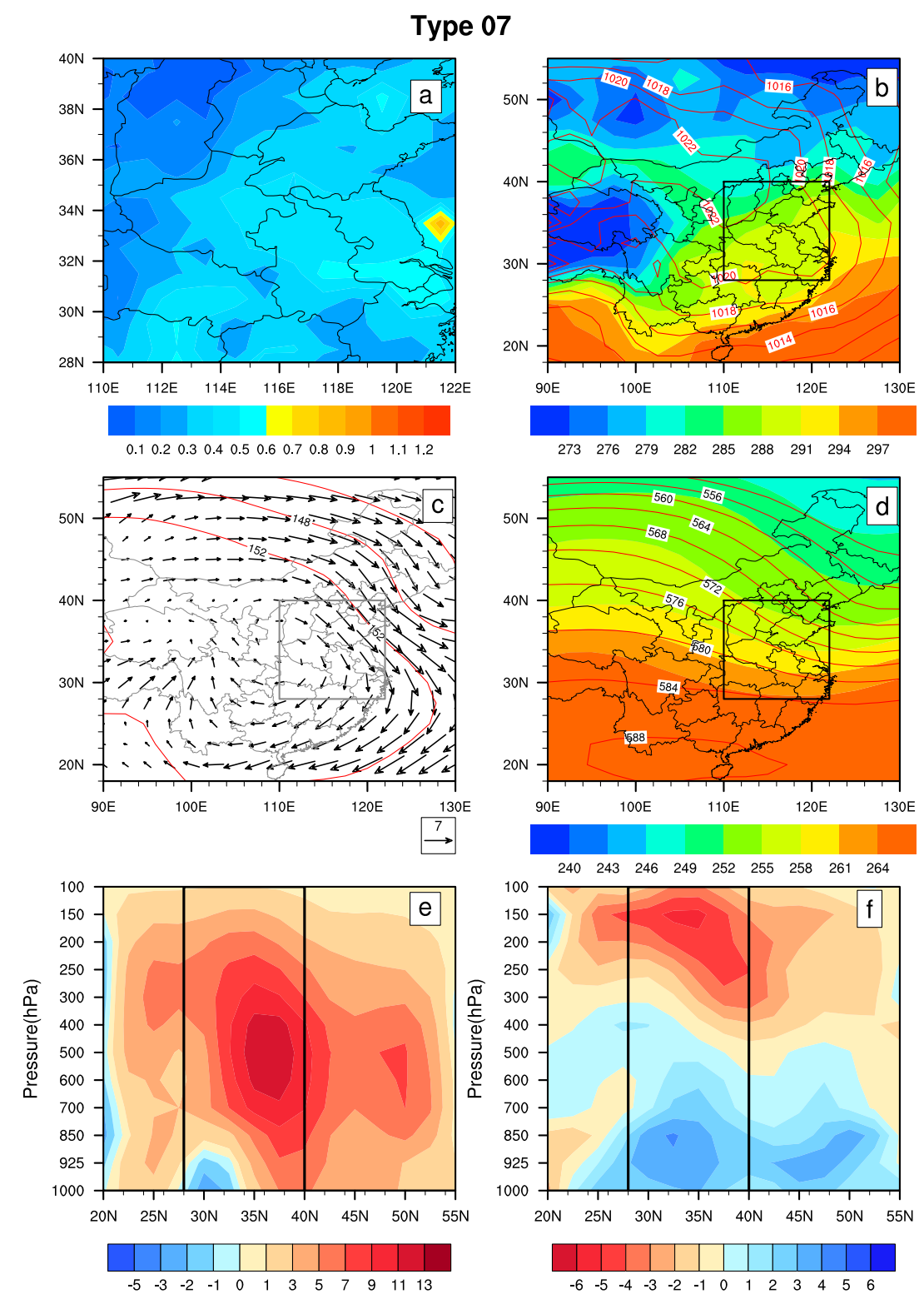

Figure 14. As in Fig. 8 but for Type 7 (clean).

\section{Discussions}

The above nine general circulation types, which are schematically illustrated in Fig. 17, correspond to different levels of air quality. In Tables 1 and 2, it can be found that the two typical cases (HE and LE) correspond to Type 4 and Type 7 respectively. To assess the relationship between diffusion conditions and synoptic patterns in autumn, the values of vertical velocity averaged from 1000 to $100 \mathrm{hPa}$ and divergence of wind field in the lower troposphere are quantitatively compared among these circulation types (Fig. 18). In this study, the climatological means are used as the threshold to discuss the diffusion ability of environment. In general, when the mean downward motion of air is strong over

eastern China with a value larger than $2.56 \times 10^{-2} \mathrm{~Pa} \mathrm{~s}^{-1}$, the divergence of low-level winds is a predominant factor in deciding the column AOD, owing to the accumulation of pollutants in low levels. As shown in Fig. 18, for the three polluted types (types $1,3,4$ ), the divergence is less than $1.79 \times 10^{-2} \mathrm{~s}^{-1}$, while for three clean types (types $7,8,9$ ) favourable divergent conditions are found. However, types 2 , 5 and 6 are recognised as the types with weak downward motion, in which the aerosols may not be gathered in the lower level. Consequently, it is necessary to account for the convergence of the middle layer due to its modification on the distribution of upper pollutants. In fact, the convergence in upper and divergence in lower levels always appear in autumn, 
Type 08
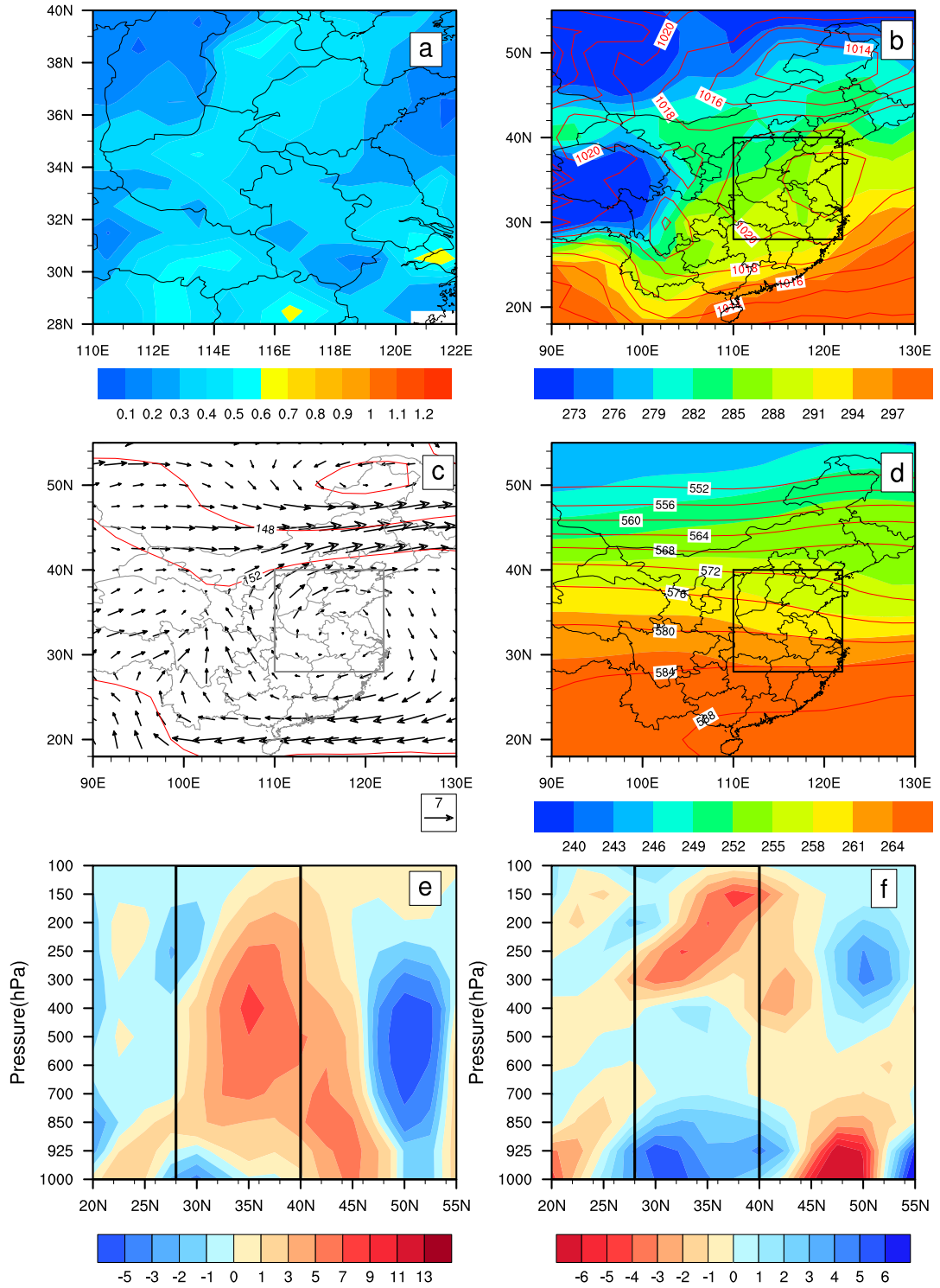

Figure 15. As in Fig. 8 but for Type 8 (clean).

which suggests that the divergence of upper-level winds is usually weaker than that of lower level or even occurring as convergence. For Type 2 and Type 5, the divergence in the middle layer are $1.08 \times 10^{-6}$ and $0.7 \times 10^{-6} \mathrm{~s}^{-1}$ respectively, which implies that the diffusion conditions of these two types are poor at both the low and middle levels. Type 6 is that with the largest (negative in pressure units) vertical velocity. The upward motion of air in the lower troposphere transports pollutants to higher levels, and the weak divergence in the middle layer $\left(0.72 \times 10^{-6} \mathrm{~s}^{-1}\right)$ leads to the severe pollution.

Admittedly, temporal and spatial variability of air pollution levels are controlled by weather conditions in conjunction with a complex distribution of emission sources. In this study, we suggested that the anthropogenic emission is almost constant in a given season followed by previous studies (Ziomas et al., 1995; Xu et al., 2011). However, the biomass burning in rural areas may cause an increase in pollution emissions. Therefore, to reduce the sudden influences from biomass burning and confirm the impact due to atmospheric conditions, we compared the types with almost the same number of fires derived from MODIS active fire product. Although the mean number of fires for types 2,3 and 7 are nearly equal $(28,31$ and 26$)$, their corresponding AOD values are different, which is resulted from different weather conditions. The diffusion in Type 7 is the best while in Type 2 it is the worst among these three types (2, 3 and 7$)$, as seen in Fig. 18. Similarly, the additional emission from burning is 


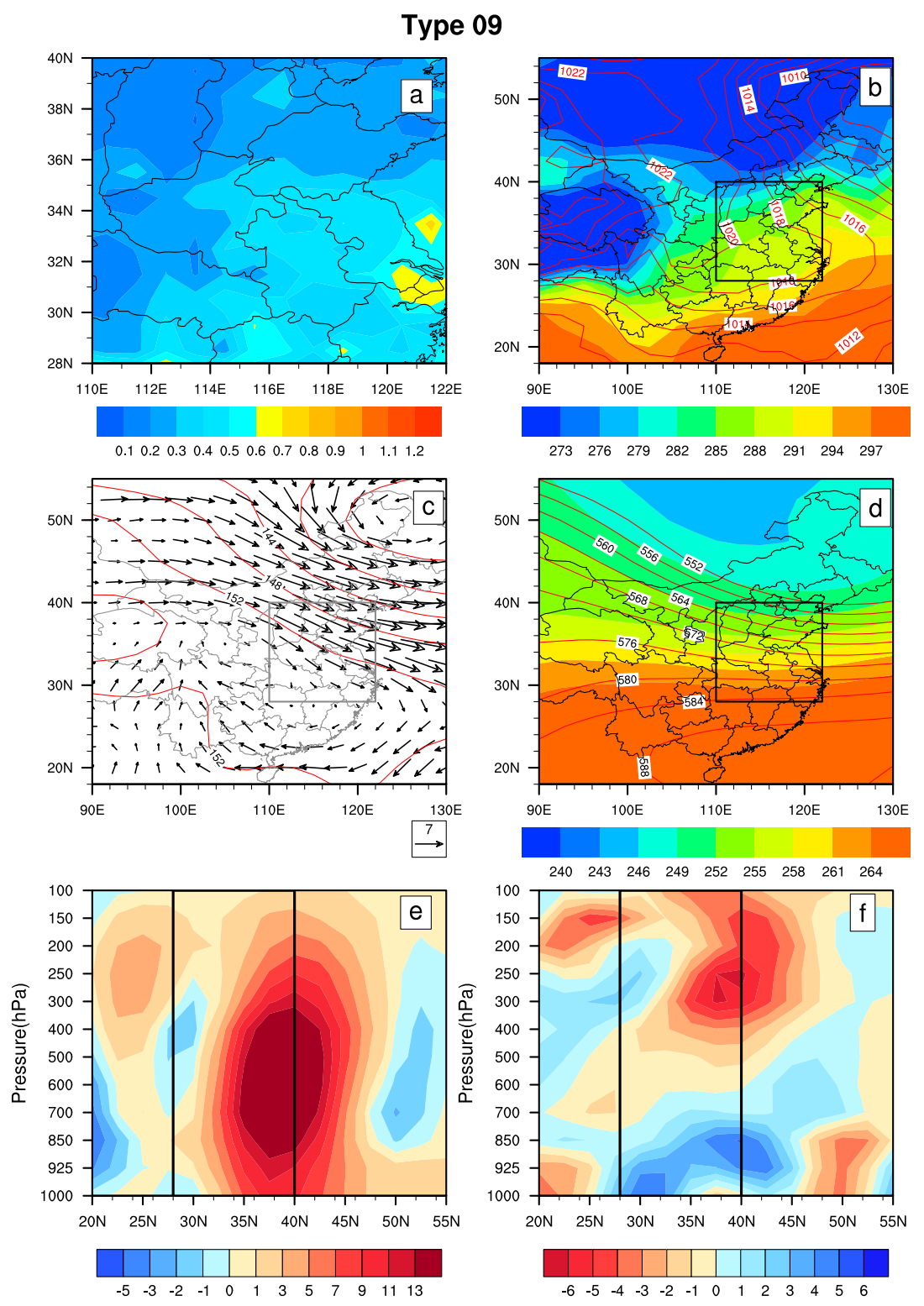

Figure 16. As in Fig. 8 but for Type 9 (clean).

similar for types 4,5 and 9 but less than that in the aforementioned three types, since the number of fires are 20,15 and 18 respectively. However, the mean AOD for Type 9 is merely half of that for types 4 and 5 owing to the difference in synoptic patterns. In addition, types 6 and 8 , with the number of fires being 9 and 7 respectively, present exactly opposite air quality, and the pollution of Type 6 is very severe, even though the number of fires of the two types are relative small compared to other types.

\section{Summary and conclusion}

In the present study, the climatological mean and interannual variation of AOD over eastern China $\left(28-40^{\circ} \mathrm{N}, 110\right.$ $\left.122^{\circ} \mathrm{E}\right)$ are investigated through statistical analysis of 10 year MODIS data (2001-2010). In consideration of weather characteristics in autumn and less variations of pollutants emission during a short time period, October is selected as a typical month to study. The air quality during the total 310 days is represented by the satellite-measured AOD, and the corresponding meteorological fields are analysed using the NCEP/NCAR reanalysis data set. Circulation patterns assessed at three levels (surface, 850 and $500 \mathrm{hPa}$ ) on episode 


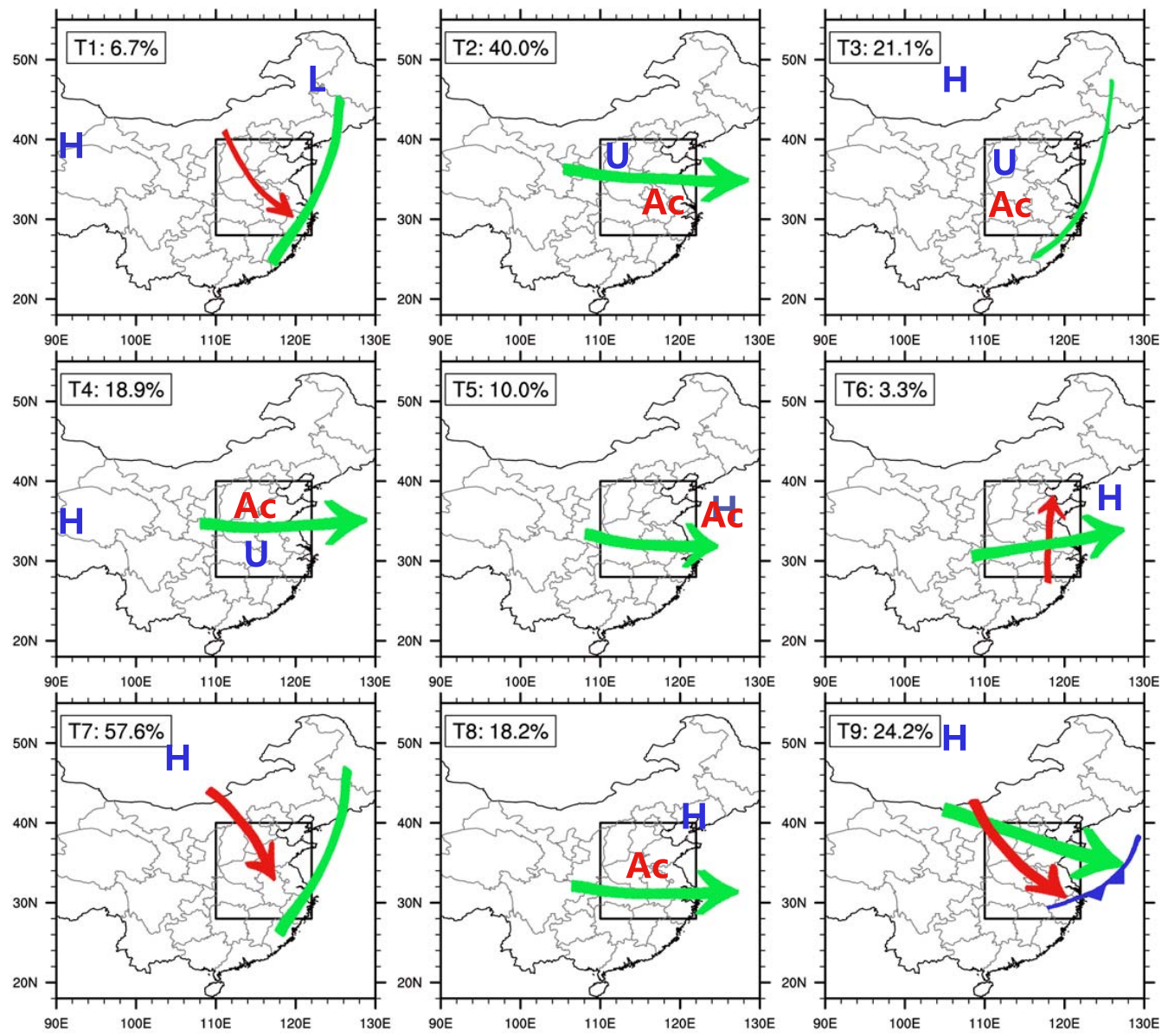

Figure 17. Schematic diagram of nine circulation types. The surface, $850 \mathrm{hPa}$ level and $500 \mathrm{hPa}$ level are shown by blue, red and green marks respectively. At the surface, "H/L" is the location of high-/low-pressure centres and " $U$ " means a uniform pressure field in eastern China. At $850 \mathrm{hPa}$, "Ac" represents for the existence of an anticyclone, and the red arrow is used to indicate the wind direction and speed. At $500 \mathrm{hPa}$, the green marks are used to indicate the direction of upper air flow or the location of the trough line.

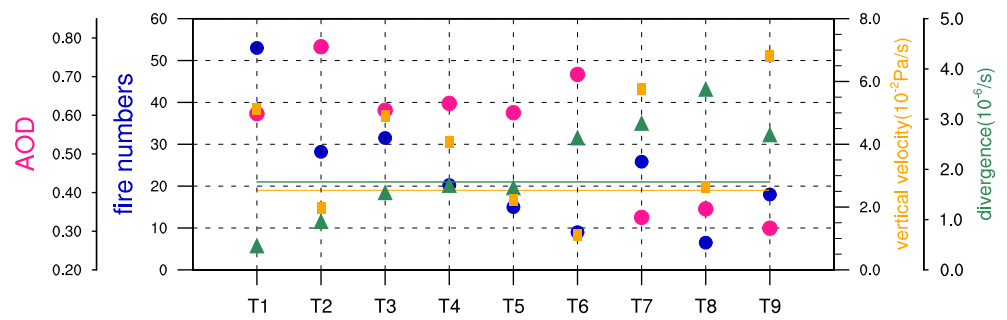

Figure 18. The values of AOD (peach), number of fires (blue), vertical velocity (orange) and divergence of low-level winds (green). The orange and green lines represent for the climatological average of vertical velocity and divergence respectively. T1-T9, namely Type 1Type 9, mean the nine different types summarised in this study.

days are identified. The main conclusions are summarised as follows.

First, the daily mean AOD value ranges from 0.3 to 0.7 in large parts of eastern China except for four widespread highvalue centres, which are considered as possible consequences of constant industrial emissions or agricultural biomass burning. The fluctuation is more volatile over the region where the mean AOD is higher. The circulation patterns indicate that eastern China is frequently dominated by large-scale stable circulation patterns in autumn, such as anticyclonic circulation at $850 \mathrm{hPa}$ and northwest flow at $500 \mathrm{hPa}$. Furthermore, since uniform descending motion prevails over the area, which gathers pollutants together in the lower layer, the 
divergence of low-level wind field plays a key role in determining the column AOD.

Moreover, two distinct extreme episodes, i.e. LE (2124 October 2003) and HE (28-31 October 2006), are selected for initial examination of the relations between meteorological field and air quality. These two episodes showed different circulation patterns at both low and high levels. Additionally, the features of two sets of backward trajectories supported the distinct distributions of AOD associated with these two episodes. To get better insight of the impact of circulation patterns on episodic pollution events over eastern China, comprehensive statistics of all 28 episodes occurred in the study period are computed and analysed. Among them there are 18 high-value episodes (90 days) and 10 low-value episodes (31 days).

Finally, according to the similarity of circulation patterns within the 28 episodes at all the three levels, the 18 polluted episodes are classified into six types, while the other 10 clean episodes are classified into three types. Each type differs from the other, either in respect to the position and intensity of weather systems or the combination of lower- and upper-level atmospheric circulations. Compared to the polluted types, generally the flows in the clean types strengthen significantly in both the middle and lower troposphere. These conditions are propitious to the horizontal diffusion of air pollutants. Particularly, patterns associated with the uniform pressure field in eastern China, with a steady westerly flow in the middle troposphere, or under the control of an anticyclone are good indications of pollution, while clean episodes occur when strong southeastward cold air advection prevails below the middle troposphere, or air masses are transported from sea to land. The values of vertical velocity and divergence of wind field are effective indices to quantitatively identify the differences in diffusion conditions for each type.

In summary, the above results have confirmed the impact of large-scale atmospheric circulations upon aerosol distributions over eastern China. Since the empirical classification of weather types are convenient to correlate different circulations patterns with the different air quality, these results are valuable for policymakers to make balanced decisions about economic activity and pollution mitigation.

Acknowledgements. We appreciate the constructive comments and suggestions by the editors and anonymous reviewers. This work is supported by CAS Strategic Priority Research Program (Grant XDA05100303), the NSFC (grant nos. 41230419, 91337213 and 41205126), Special Funds for Public Welfare of China (grant GYHY201306077) and the Jiangsu Provincial 2011 Program (Collaborative Innovation Center of Climate Change).

Edited by: X. Liu

\section{References}

Al-Saadi, J., Szykman, J., Pierce, R. B., Kittaka, C., Neil, D., Chu, D. A., Remer, L., Gumley, L., Prins, E., Weinstock, L., Macdonald, C., Wayland, R., Dimmick, F., and Fishman, J.: Improving national air quality forecasts with satellite aerosol observations, B. Am. Meteorol. Soc., 86, 1249-1261, 2005.

Borge, R., Lumbreras, J., Vardoulakis, S., Kassomenos, P., and Rodríguez, E.: Analysis of long-range transport influences on urban $\mathrm{PM}_{10}$ using two-stage atmospheric trajectory clusters, Atmos. Environ., 41, 4434-4450, 2007.

Chen, B., Stein, A. F., Maldonado, P. G., Sanchez de la Campa, A. M., Gonzalez-Castanedo, Y., Castell, N., and de la Rosa, J. D.: Size distribution and concentrations of heavy metals in atmospheric aerosols originating from industrial emissions as predicted by the HYSPLIT model, Atmos. Environ., 71, 234-244, 2013.

Chen, S., Zhao, C., Qian, Y., Leung, L. R., Huang, J., Huang, Z., Bi, J., Zhang, W., Shi, J., Yang, L., Li, D., and Li, J.: Regional modeling of dust mass balance and radiative forcing over East Asia using WRF-Chem, Aeolian Res., 15, 15-30, 2014.

Chen, S. Y., Huang, J. P., Fu, Q., Ge, J. M., and Su, J.: Effects of aerosols on autumn precipitation over mid-eastern China, J. Trop. Meteor., 27, 339-347, 2012 (in Chinese).

Chen, X. L., Fan, S. J., Li, J. N., Liu, J., Wang, A. Y., and Fong, S. K.: The typical weather characteristics of air pollution in Hong Kong area, J. Trop. Meteor., 24, 195-199, 2008 (in Chinese).

Chen, Y., Zhao, C., Zhang, Q., Deng, Z., and Huang, M.: Aircraft study of Mountain Chimney Effect of Beijing, China, J. Geophys. Res., 114, D08306, doi:10.1029/2008JD010610, 2009.

Chen, Z. H., Cheng, S. Y., Li, J. B., Guo, X. R., Wang, W. H., and Chen, D. S.: Relationship between atmospheric pollution processes and synoptic pressure patterns in northern China, Atmos. Environ., 42, 6078-6087, 2008.

Cheng, S. Y., Chen, D. S., Li, J. B., Wang, H. Y., and Guo, X. R.: The assessment of emission-source contributions to air quality by using a coupled MM5-ARPS-CMAQ modeling system: a case study in the Beijing metropolitan region, China, Environ. Modell. Softw., 22, 1601-1616, 2007.

Chu, D. A., Kaufman, Y. J., Ichoku, C., Remer, L. A., Tanré, D., and Holben, B. N.: Validation of MODIS aerosol optical depth retrieval over land, Geophys. Res. Lett., 29, 8007, doi:10.1029/2001GL013205, 2002.

Csavina, J., Field, J., Félix, O., Corral-Avitia, A. Y., Eduardo Sáez, A., and Betterton, E. A.: Effect of wind speed and relative humidity on atmospheric dust concentrations in semi-arid climates, Sci. Total Environ., 487, 82-90, 2014.

Demuzere, M., Trigo, R. M., Vila-Guerau de Arellano, J., and van Lipzig, N. P. M.: The impact of weather and atmospheric circulation on $\mathrm{O}_{3}$ and $\mathrm{PM}_{10}$ levels at a rural mid-latitude site, Atmos. Chem. Phys., 9, 2695-2714, doi:10.5194/acp-9-2695-2009, 2009.

Ding, A. J., Wang, T., Zhao, M., Wang, T., and Li, Z.: Simulation of sea-land breezes and a discussion of their implications on the transport of air pollution during a multi-day ozone episode in the Pearl River Delta of China, Atmos. Environ., 38, 6737-6750, 2004.

Ding, A. J., Wang, T., Thouret, V., Cammas, J.-P., and Nédélec, P.: Tropospheric ozone climatology over Beijing: analysis of aircraft 
data from the MOZAIC program, Atmos. Chem. Phys., 8, 1-13, doi:10.5194/acp-8-1-2008, 2008.

Ding, A. J., Wang, T., Xue, L. K., Gao, J., Stohl, A., Lei, H. C., Jin, D. Z., Ren, Y., Wang, Z. F., Wei, X. L., Qi, Y. B., Liu, J., and Zhang, X. Q.: Transport of north China midlatitude cyclones: Case study of aircraft measurements in summer 2007, J. Geophys. Res., 114, D08304, doi:10.1029/2008JD011023, 2009.

Donaldson, K., Stone, V., Seaton, A., and MacNee, W.: Ambient particle inhalation and the cardiovascular system: Potential mechanisms, Environ. Health. Persp., 109, 523-527, 2001.

Draxler, R. R. and Hess, G. D.: Description of the HYSPLIT_4 modeling system, NOAA Technical Memorandum ERL ARL224, 1997.

Flocas, H., Kelessis, A., Helmis, C., Petrakakis, M., Zoumakis, M., and Pappas, K.: Synoptic and local scale atmospheric circulation associated with air pollution episodes in an urban Mediterranean area, Theor. Appl. Climatol., 95, 265-277, 2009.

Guo, Y. F., Li, D. Y., Zhou, B., Xia, J., Wu, Y., and Hu, Y. H.: Study on haze characteristics in Wuxi and its impact factors, Meteor. Mon., 39, 1314-1324, 2013 (in Chinese).

He, Q. S., Li, C. C., Geng, F. H., Lei, Y., and Li, Y. H.: Study on long-term aerosol distribution over the land of east China using MODIS data, Aerosol Air Qual. Res., 12, 304-319, 2012.

Janssen, N. A., Hoek G., Simic-Lawson, M., Fischer, P., van Bree, L., ten Brink, H., Keuken, M., Atkinson, R. W., Anderson, H. R., Brunekreef, B., and Cassee, F. R.: Black carbon as an additional indicator of the adverse health effects of airborne particles compared with $\mathrm{PM}_{10}$ and $\mathrm{PM}_{2.5}$, Environ. Health. Persp., 119, 1691-1699, 2011.

Kan, H. and Chen, B.: Particulate air pollution in urban areas of Shanghai, China: health-based economic assessment, Sci. Total Environ., 322, 71-79, 2004.

Kassomenos, P. A., Sindosi, O. A., Lolis, C. J., and Chaloulakou, A.: On the relation between seasonal synoptic circulation types and spatial air quality characteristics in Athens, Greece, J. Air. Waste. Manage., 53, 309-324, 2003.

Kaufman, Y. J., Tanre, D., and Boucher, O.: A satellite view of aerosols in the climate system, Nature, 419, 215-223, 2002.

Kim, S. W., Yoon, S. C., Kim, J. Y., and Kim, S. Y.: Seasonal and monthly variations of columnar aerosol optical properties over East Asia determined from multi-year MODIS, LIDAR, and AERONET sun/sky radiometer measurements, Atmos. Environ., 41, 1634-1651, 2007.

Koren, I., Altaratz, O., Remer, L. A., Feingold, G., Martins, J. V., and Heiblum, R. H.: Aerosol-induced intensification of rain from the tropics to the mid-latitudes, Nat. Geosci., 5, 118-122, doi:10.1038/NGEO1364, 2012.

Li, Z. Q., Niu, F., Fan, J. W., Liu, Y. G., Rosenfeld, D., and Ding, Y. N.: Long-term impacts of aerosols on the vertical development of clouds and precipitation, Nat. Geosci., 4, 888-894, doi:10.1038/NGEO1313, 2011.

Lin, J., Nielsen, C. P., Zhao, Y., Lei, Y., Liu, Y., and Mcelroy, M. B.: Recent changes in particulate air pollution over China observed from space and the ground: effectiveness of emission control, Environ. Sci. Technol., 44, 7771-7776, 2010.

Liu, Y. K., Liu, J. F., and Tao, S.: Interannual variability of summertime aerosol optical depth over East Asia during 2000-2011: a potential influence from El Niño Southern Oscillation, Environ. Res. Lett., 8, 044034, doi:10.1088/1748-9326/8/4/044034, 2013.
Luo, Y. X., Zheng, X. B., Zhao, T. L., and Chen, J.: A climatology of aerosol optical depth over China from recent 10 years of MODIS remote sensing data, Int. J. Climatol., 34, 863-870, 2014.

Rosenfeld, D., Cattani, E., Melani, S., and Levizzani, V.: Considerations on Daylight Operation of 1.6-VERSUS 3.7- $\mu$ m Channel on NOAA and Metop Satellites, B. Am. Meteorol. Soc., 85, 873881, 2004.

Rosenfeld, D., Dai, J., Yu, X., Yao, Z. Y., Xu, X. H., Yang, X., and $\mathrm{Du}, \mathrm{C}$. L.: Inverse relations between amounts of air pollution and orographic precipitation, Science, 315, 1396-1398, 2007.

Russo, A., Trigo, R. M., Martins, H., and Mendes, M. T.: $\mathrm{NO}_{2}$, $\mathrm{PM}_{10}$ and $\mathrm{O}_{3}$ urban concentrations and its association with circulation weather types in Portugal, Atmos. Environ., 89, 768-785, 2014.

Saavedra, S., Rodríguez, A., Taboada, J. J., Souto, J. A., and Casares, J. J.: Synoptic patterns and air mass transport during ozone episodes in northwestern Iberia, Sci. Total Environ., 441, 97-110, 2012.

Shahgedanova, M., Burt, T. P., and Davies, T. D.: Synoptic climatology of air pollution in Moscow, Theor. Appl. Climatol., 61, 85-102, 1998.

Tanner, P. A. and Law, P. T.: Effects of synoptic weather systems upon the air quality in an Asian megacity, Water Air Soil Poll., 136, 105-124, 2002.

Twohy, C. H., Coakley, J. A., and Tahnk, W. R.: Effect of changes in relative humidity on aerosol scattering near clouds, J. Geophys. Res., 114, D05205, doi:10.1029/2008JD010991, 2009.

Twomey S.: The influence of pollution on the shortwave albedo of clouds, J. Atmos. Sci., 34, 1149-1152, 1977.

Wang, J., Li, J. L., and Zhang, Y. H.: Weather situation classification and its feature in severe air pollution days in winter in Urumqi, J. Meteorol. Environ., 29, 28-32, 2013 (in Chinese).

Wang, S. X. and Zhang, C. Y.: Spatial and temporal distribution of air pollutant emissions from open burning of crop residues in China, Science paper Online, 3, 329-333, 2008 (in Chinese).

Wang, X. Q., Qi, Y. B., Wang, Z. F., Guo, H., and Yu, T.: The influence of synoptic pattern on $\mathrm{PM}_{10}$ heavy air pollution in Beijing, Climatic Environ. Res., 12, 81-86, 2007 (in Chinese).

Wu, J., Guo, J., and Zhao, D. M.: Characteristics of aerosol transport and distribution in East Asia, Atmos. Res., 132, 185-198, 2013.

Xin, J. Y., Zhang, Q., Wang, L. L., Gong, C. S., Wang, Y. S., Liu, Z. R., and Gao, W. K.: The empirical relationship between the $\mathrm{PM}_{2.5}$ concentration and aerosol optical depth over the background of North China from 2009 to 2011, Atmos. Res., 138, 179-188, 2014.

Xu, W. Y., Zhao, C. S., Ran, L., Deng, Z. Z., Liu, P. F., Ma, N., Lin, W. L., Xu, X. B., Yan, P., He, X., Yu, J., Liang, W. D., and Chen, L. L.: Characteristics of pollutants and their correlation to meteorological conditions at a suburban site in the North China Plain, Atmos. Chem. Phys., 11, 4353-4369, doi:10.5194/acp-114353-2011, 2011.

Yang, Y. J., Fu, Y. F., Wu, B. W., Shi, C. E., Deng, X. L., Zhang, H., and Zhang, Y.: Impacts of Agricultural Fire on Aerosol Distribution over East China during Summer Harvest time, Journal of Atmospheric and Environmental Optics, 8, 241-252, 2013 (in Chinese).

Zhang, L., Liao, H., and Li, J. P.: Impacts of Asian summer monsoon on seasonal and interannual variations of 
aerosols over eastern China, J. Geophys. Res., 115, D00K05, doi:10.1029/2009JD012299, 2010.

Zhao, C., Wang, Y., Yang, Q., Fu, R., Cunnold, D., and Choi, Y.: Impact of East Asian summer monsoon on the air quality over China: View from space, J. Geophys. Res., 115, D09301, doi:10.1029/2009JD012745, 2010.

Zhao, C., Liu, X., and Leung, L. R.: Impact of the Desert dust on the summer monsoon system over Southwestern North America, Atmos. Chem. Phys., 12, 3717-3731, doi:10.5194/acp-12-37172012, 2012.

Zhao, C., Leung, L. R., Easter, R., Hand, J., and Avise, J.: Characterization of speciated aerosol direct radiative forcing over California, J. Geophys. Res., 118, 2372-2388, doi:10.1029/2012JD018364, 2013a.

Zhao, C., Liu, X., Qian, Y., Yoon, J., Hou, Z., Lin, G., McFarlane, S., Wang, H., Yang, B., Ma, P.-L., Yan, H., and Bao, J.: A sensitivity study of radiative fluxes at the top of atmosphere to cloudmicrophysics and aerosol parameters in the community atmosphere model CAM5, Atmos. Chem. Phys., 13, 10969-10987, doi:10.5194/acp-13-10969-2013, 2013 b.
Zhao, C. S., Tie, X. X., and Lin, Y. P.: A possible positive feedback of reduction of precipitation and increase in aerosols over eastern central China, Geophys. Res. Lett., 33, L11814, doi:10.1029/2006GL025959, 2006a.

Zhao, C. S., Tie, X. X., Brasseur, G., Noone, K. J., Nakajima, T., Zhang, Q., Zhang, R. Y., Huang, M. Y., Duan, Y., Li, G. L., and Ishizaka, Y.: Aircraft measurements of cloud droplet spectral dispersion and implications for indirect aerosol radiative forcing, Geophys. Res. Lett., 33, L16809, doi:10.1029/2006GL026653,2006b.

Ziomas, I., Melas, D., Zerefos, C., Bais, A., and Paliatsos, A.: Forecasting peak pollutant levels from meteorological variables, Atmos. Environ., 29, 3703-3711, 1995. 